\title{
Retrieval of Aerosol Optical Thickness in the Arctic Snow-Covered Regions Using Passive Remote Sensing: Impact of Aerosol Typing and Surface Reflection Model
}

\author{
Linlu Mei ${ }^{\circledR}$, Vladimir Rozanov, Christoph Ritter, Bernd Heinold, Ziti Jiao ${ }^{\circledR}$, \\ Marco Vountas $^{(}$, and John P. Burrows ${ }^{(1)}$
}

\begin{abstract}
Currently, no aerosol optical thickness (AOT) data set over the Arctic snow/ice-covered regions derived from spaceborne passive remote sensing is available. The challenge is to develop an accurate and robust technique to derive AOT above highly variable and bright snow/ice surfaces. To extend data coverage of the eXtensible Bremen Aerosol/cloud and surfacE Retrieval (XBAER) AOT data product in the future, we propose a new algorithm for the retrieval of AOT and surface properties over snow/ice simultaneously. The algorithm utilizes the linear perturbation theory and does not use any simplified atmospheric correction techniques. Key issues like the selection of a proper aerosol type and optimal surface parameterization method for the retrieval of AOT over the Arctic have been investigated. The aerosol type is investigated using the aerosol climatology microphysical properties derived from four Aerosol Robotic Network (AERONET) sites (Barrow, Hornsund, Kangerlussuaq, and Tiksi). The three-parametric Ross-Li linear kernel model is used to describe the snow bidirectional reflectance distribution function (BRDF). The a priori knowledge of wavelengthdependent features of the coefficients in the Ross-Li linear kernel model is derived from Polarization and Directionality of the Earth's Reflectances (POLDER) measurements over the Arctic and utilized as constraints in the retrieval. The studies show that the combination of Ross-Li surface model and weakly absorbing aerosol parameterization provides an optimal way to derive AOT over the Arctic snow/ice-covered regions from passive remote sensing observations. The retrieved AOTs using POLDER show good agreement with AERONET observations.
\end{abstract}

Manuscript received June 13, 2019; revised October 15, 2019 and January 20, 2020; accepted February 4, 2020. Date of publication February 21, 2020; date of current version June 24, 2020. This work was supported by the SFB/TR 172 "ArctiC Amplification: Climate Relevant Atmospheric

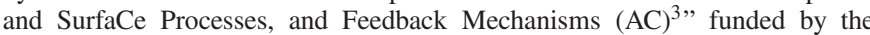
German Research Foundation (DFG, Deutsche Forschungsgemeinschaft). (Corresponding author: Linlu Mei.)

Linlu Mei, Vladimir Rozanov, Marco Vountas, and John P. Burrows are with the Institute of Environmental Physics, University of Bremen, 28359 Bremen, Germany (e-mail: mei@iup.physik.uni-bremen.de).

Christoph Ritter is with the Alfred Wegener Institute, 14473 Potsdam, Germany.

Bernd Heinold is with the Leibniz Institute for Tropospheric Research (TROPOS), 04318 Leipzig, Germany.

Ziti Jiao is with the State Key Laboratory of Remote Sensing Science, Jointly Sponsored by the Beijing Normal University and the Institute of Remote Sensing and Digital Earth of the Chinese Academy of Sciences, Beijing 100875, China, and also with the Beijing Engineering Research Center for Global Land Remote Sensing Products, Institute of Remote Sensing Science and Engineering, Faculty of Geographical Science, Beijing Normal University, Beijing 100875, China.

Color versions of one or more of the figures in this article are available online at http://ieeexplore.iee.org.

Digital Object Identifier 10.1109/TGRS.2020.2972339
Index Terms-Aerosol, arctic, retrieval, satellite, snow-covered.

\section{INTRODUCTION}

C ONDITIONS in the Arctic have been changing significantly during the period of Arctic amplification (AA) [1]. For example, surface air temperature in the Arctic has risen approximately twice as that of the rest of the world [2]. The reasons for AA are thought to be dominated by atmospheric processes [3]. The conditions in the period of the AA influence sea ice extent, the aerosol transport, hydrological cycle, permafrost, and oceanic conditions [4], [5]. As a result of the increase in human activities in the Arctic, air pollution is likely to have an increasingly important impact on the Arctic environment [6], [7]. The Arctic air temperatures have been observed to be warmer over the past five years (2014-2018) than any previous five-year period since 1900 [8], and the sea ice summer/winter extent in 2018 was the sixth/second lowest during the period 1979-2018 [9]. Consequently, the Arctic ecosystem is being altered. There are also potential effects at low-mid-latitudes [10].

Aerosols are short-lived climate forcing agents [11]. They affect the Arctic climate: 1) through direct radiative effects, such as backscattering or absorption of incoming solar irradiance and 2) indirectly by playing an essential role in cloud formation and by being deposited on snow and ice, and thereby darkening the surface, particularly in the visible wavelength range [12]-[14].

Arctic aerosols originate from both local and remote sources. Polluted aerosol, entering the Arctic and containing sulfate, $\mathrm{SO}_{4}^{2-}$, and particulate organic matter, ammonium nitrate, $\mathrm{NH}_{4} \mathrm{NO}_{3}$, dust, and black carbon (BC), produce the Arctic haze [15]. Such events were already observed in the nineteenth century [16]. Advected aerosol, containing BC, is considered to be a strong warming short-lived radiative forcing agent [15], [17]. Other anthropogenic aerosols also contribute to the Arctic haze events [20]-[22]. Rahn et al. [18] and Stone et al. [19] also reported the transport of Asian dust as a source of the Arctic haze.

In addition to advected aerosols, local sources are becoming increasingly important in the warming Arctic [23]. Approximately four million people now live in the Arctic. Gabric et al. [24] reported that the local marine biogenic aerosol is one of the key drivers for the seasonal changes 
in sea ice and ocean biology in the Arctic. Park et al. [25] found varying regional relationships between the atmospheric dimethyl sulfide, $\mathrm{CH}_{3} \mathrm{SCh}_{3}$, and the exposure of the air mass to the phytoplankton biomass in the remote Arctic ocean (Svalbard: $78.5^{\circ} \mathrm{N}, 11.8^{\circ} \mathrm{E}$ ). Local Arctic air pollution (e.g., shipping, oil extraction, flaring, or metal smelting) has previously been reported to be negligible but it is now considered to be a serious and growing problem in these fragile environments [7], [26]. The impacts of shipping and other emission sources on the Arctic atmospheric environment have also been investigated $[27[-[30]$.

Local measurements and campaign-oriented process and/or model studies have provided most of our current understanding. Studies, within the collaborative research center $\mathrm{AC}^{3}$ (Arctic Amplification: Climate Relevant Atmospheric and SurfaCe Processes, and Feedback Mechanisms [31]), such as the "Arctic CLoud Observations Using airborne measurements during polar Day/"Physical feedbacks of Arctic boundary layer, Sea ice, Cloud, and AerosoL (ACLOUD/PASCAL) campaigns delivered a wealth of valuable contributions to several aerosol-related questions to understand the impacts of Arctic clouds and aerosol on the Arctic climate system [3]. Currently, the Multidisciplinary drifting Observatory for the Study of Arctic Climate (MOSAiC) is taking place. It has been designed to investigate the processes in the atmosphere-iceocean system and its impact on the sea-ice mass and energy budgets (https://www.mosaic-expedition.org/).

Details of other relevant major Arctic campaigns can be found in [3, Table 2] and other efforts have been made to use individual in situ measurements [32]. The global aerosolclimate module ECHAM-HAM [33], [34] has been used to investigate aerosol effects in the Arctic [14], [35].

However, only a few studies have investigated Arctic aerosol properties (e.g., aerosol optical thickness, AOT, for instance) using satellite observations, particularly passive satellites. One reason is that no such AOT data sets using satellite-borne passive remote sensing over the Arctic snow/ice-covered regions are available [23]. Istomina et al. [36] and Mei et al. [37], [38] prepared the necessary algorithms, which can be used to create such a data set. However, up to now, the algorithms remained only as prototypes and have not been applied operationally to produce publicly available data products. This is attributed to issues associated with cloud screening, aerosol typing, and surface parameterization.

This article introduces a new method to retrieve AOT accurately over the Arctic cryosphere and should enable us to create a climatological aerosol long-term series. Although there is no doubt that active sensors aboard satellite platforms deliver a wealth of important aerosol and cloud properties, their coverage is sparse. This article focuses on a new and independent methodology based on satellitesensor's multispectrum multiviewing capabilities. The latter (multispectrum multiviewing) are important instrumental features that allow sophisticated retrievals to separate the contribution of aerosols and snow/ice-covered surfaces from the top-of-atmosphere (TOA) reflectance. This study describes the algorithm which has been developed for use with the measurements of the instrument POLarization and Directionality of the Earth's Reflectances (POLDER) aboard the PARASOL satellite and its prerequisites. It is part of the eXtensible Bremen Aerosol/cloud and surfacE Retrieval (XBAER) algorithm [39] family, to the Arctic snow/ice-covered regions. The XBAER algorithm has been applied to produce AOT data set over both dark and moderately bright surfaces under cloud/snow-free conditions [39], [40] using the measurements of different instruments [39], [41]. It is also able to retrieve both cloud properties [42] and cloud/aerosol properties when cloud and aerosol are present [43].

This article describes: 1) the assumptions and theoretical concepts of this novel retrieval algorithm and 2) the method used for aerosol typing and surface parameterization. The sensitivity of the retrieval is investigated using synthetic data. A first comparison with ground-based measurement data from the Aerosol Robotic Network (AERONET) measurement network to validate in a preliminary manner data set is presented. It should be noted that a full validation of the presented algorithm would go beyond the scope of this article and it will be presented in a subsequent article.

The aerosol properties exploited in this study are described in Section II. The aerosol characterization over the Arctic region is presented in Section III. Section IV describes the newly developed retrieval algorithm, and investigation of impacts of using different Arctic aerosol types and surface models on satellite aerosol retrieval is presented in Section V. The results of POLDER-derived AOT and the comparison with AERONET observations are given in Section VI. Finally, the conclusions are given in Section VII.

\section{Aerosol Properties}

In the following, we briefly introduce quantities that will be used in Section III to characterize Arctic aerosol in a representative fashion. We use quantities that are readily provided by the AERONET, which is a network of groundbased Sun-sky scanning radiometers for aerosol monitoring [44]. Including sites all over the world, with several ones operated in the Arctic over a sufficiently long period.

\section{A. Aerosol Optical Thickness}

AOT is widely used in global climate modeling [45], [46] and environment-related studies [47]. The AOT $\left(\tau_{\lambda}\right)$ is defined as follows:

$$
\tau_{\lambda}=\int_{0}^{H} k_{\lambda}(z) d z
$$

where $k_{\lambda}(z)$ is the aerosol extinction coefficient at wavelength $\lambda$ and height $z$, which includes both scattering and absorption. $H$ is the height of TOA. AOT is used to represent aerosol (e.g., urban haze, smoke particles, desert dust, and sea salt) burden along the total column of the atmosphere [44].

Wavelength-dependent AOT can be used to derive another parameter, which is closely linked to the particle size distribution (PSD) function [49], e.g., Ångström exponent, $\alpha$, [48]

$$
\alpha=-\ln \left(\tau\left(\lambda_{2}\right) / \tau\left(\lambda_{1}\right) / \ln \left(\lambda_{2} / \lambda_{1}\right)\right.
$$

where $\lambda_{1}$ and $\lambda_{2}$ are two wavelengths. If the Ångström exponent value is small, $\alpha$ indicates large aerosol particles, 
whereas large values show small particles. This behavior is used to distinguish different aerosol sources [50]. AOT measurements are routinely performed at AERONET stations. The uncertainties of AERONET AOT is less than 0.01 for $\lambda>440 \mathrm{~nm}$ and less than 0.02 for shorter wavelengths [44] under cloud-free conditions.

\section{B. Fine Mode Fraction}

The fine-mode fraction (FMF) is a parameter used to describe the proportion of small particles to the total-column aerosol [51], [52]. The smaller particles are referred to as the fine-mode or accumulation-mode parts in the aerosol PSD. The definition of FMF is different in different scientific communities. For the community focusing on satellite instrumentation, the $\operatorname{FMF}(f)$ is defined as follows:

$$
f=\frac{\tau_{f}(\lambda)}{\tau(\lambda)}
$$

where $\tau_{f}(\lambda)$ and $\tau(\lambda)$ are fine-mode AOT and total-column AOT at wavelength $\lambda$, respectively. Fine-mode AOT refers to AOT for aerosol particles with particle size smaller than a given particle effective radius.

The spectral deconvolution algorithm (SDA) is used to produce the AERONET FMF product [48]

$$
f=\frac{\alpha-\alpha_{c}}{\alpha_{f}-\alpha_{c}}
$$

where $\alpha_{f}$ and $\alpha_{c}$ are Ångström exponents for fine and coarse mode, respectively. The AERONET version 3 [53] FMF product is used as a reference to validate other satellite products, although limitations of AERONET SDA product in the presence of cirrus clouds have been reported recently [54]. The uncertainty of AERONET FMF is about 0.1 [48].

\section{Particle Size Distribution}

The PSD of aerosol particles is important because: 1) it links to the aerosol physical and/or chemical properties, which further reflects the radiation transfer in the aerosol system; 2) the aerosol chemical composition is found to be sizedependent; and 3) small particles, which may have a strong impact on human health need to be characterized by the PSD [55]. The most well-used aerosol PSDs include normal distribution [56], lognormal distribution [56], modified gamma distribution [57], and the power-law function (e.g., Junge distribution) [58]. A bimodal lognormal distribution is generally considered adequate to model the PSD by the satellite research community [59], [60]. The bimodal lognormal distribution uses a combination of fine and coarse modes to describe the PSD. In AERONET observation, the volume-based PSD is retrieved for 22 logarithmically equidistant discrete points in the range of size -0.05 to $15 \mu \mathrm{m}$. The uncertainty of AERONET PSD is $35 \%-100 \%$ for each bin of the PSD [61].

\section{Refractive Indices}

The retrieval of AOT uses our understanding of the interaction of electromagnetic radiation with the aerosol particles.

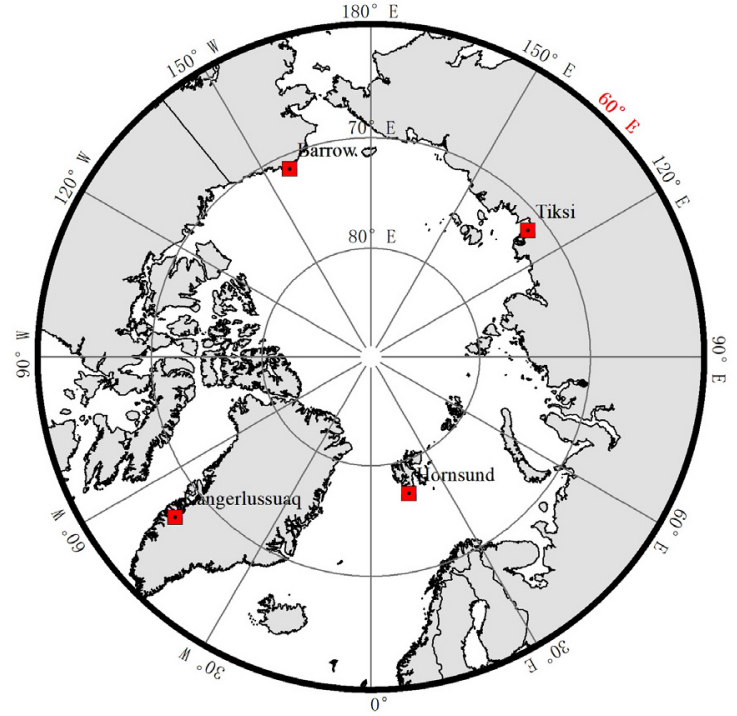

Fig. 1. AERONET site distribution. Locations are labeled with red squares.

For a certain PSD, knowledge of aerosol scattering and absorption is needed. The wavelength-dependent refractive index (RI) is described by $m=n+k i$, where the real part $(n)$ describes the scattering, and the imaginary part $(k)$ describes the absorption. The ranges of the real and imaginary parts of the RI in AERONET observations are [1.33-1.6] and [0.0005-0.5], respectively. Accurate RI, in conjunction with PSD, is required to determine the amount of aerosol scattering and absorption properties, which is important to understand the impact of aerosol particles on direct radiative forcing [62]. The uncertainties of RI are 0.04 for the real part and about 50\% for the imagery part [61].

\section{Aerosol Characterization Over THE ARCTIC REGIONS}

Measurements from four AERONET sites located inside the Arctic circle (latitude larger than $60^{\circ} \mathrm{N}$ ) are used to investigate the aerosol properties in the Arctic regions. Those four sites are Barrow $\left(71.3^{\circ} \mathrm{N}, 156.7^{\circ} \mathrm{W}\right)$ in Alaska, Kangerlussuaq $\left(67.01^{\circ} \mathrm{N},-50.7^{\circ} \mathrm{W}\right)$ in western Greenland, Hornsund $\left(77.0^{\circ} \mathrm{N}, 15.6^{\circ} \mathrm{E}\right)$ in southern Svalbard, and Tiksi $\left(71.6^{\circ} \mathrm{N}\right.$, $\left.128.9^{\circ} \mathrm{E}\right)$ at the shore of the Laptev Sea in Russia. The geographical distribution of the four sites is shown in Fig. 1. These four sites are chosen using the following criteria: 1) the objective of having a balanced geographical distribution of the sites within the Arctic circle; 2) the representativeness of the aerosol conditions (aerosol types and loading); 3) knowledge gained from previous publications (sites frequently used in the literature) [23], [65]; and 4) the AERONET stations having sufficiently long multiyear observation records. The selected sites represent different cases of natural conditions and anthropogenic influence ranging from clean remote sites (Kangerlussuaq) to rather polluted sites (Barrow, Hornsund, and Tiksi). The site in Kangerlussuaq is used to investigate the Arctic background condition under clean days. Barrow is reported to be affected by biomass burning [63] and dust 


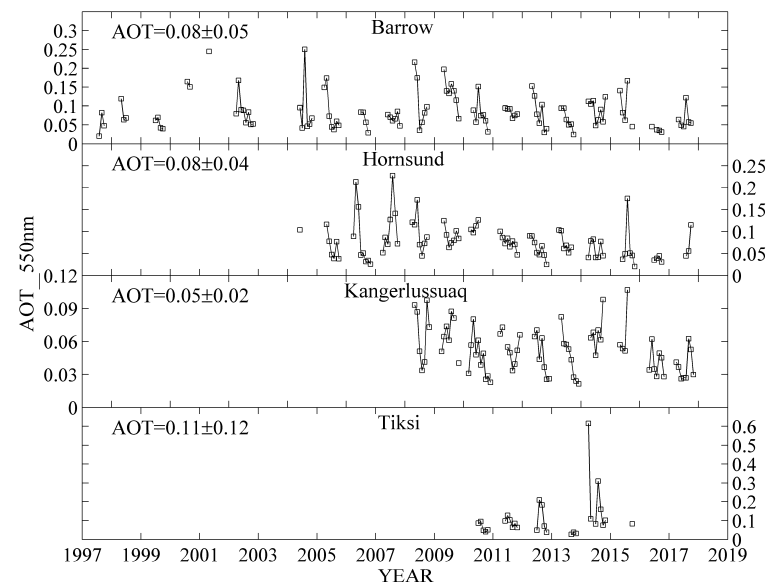

Fig. 2. Monthly mean AOT over selected sites. The values of AOT in the top left corner of each panel are the average of all monthly mean values.

transport [19] while Tiksi is affected by the Russian agricultural combustion [64] and ship emissions [65]. In the following sections, Arctic aerosol properties such as AOT at $550 \mathrm{~nm}$, FMF, PSD, and RI for four wavelengths (440, 675, 870, and $1020 \mathrm{~nm})$, will be presented and discussed.

\section{A. AOT and FMF}

Fig. 2 shows the monthly mean AOT at $550 \mathrm{~nm}$ (we refer the AOT hereafter to a wavelength of $550 \mathrm{~nm}$ ) calculated using the AERONET version 3 level 2.0 observations over the selected sites. There are at least two reasons to use a wavelength of $550 \mathrm{~nm}$ as the reference wavelength. First, AOT at $550 \mathrm{~nm}$ is a common parameter almost for all aerosol satellite products. Second, according to the MODIS aerosol type parameterization, adopted in our retrieval algorithm, the aerosol microphysical properties such as RI and size distribution are functions of AOT at $550 \mathrm{~nm}$. The values of AOT in the top left corner of each panel are the averaged $\mathrm{AOT} \pm \sigma$ (one standard deviation). The AOT values are in general smaller over Hornsund and Kangerlussuaq located far from human activities or not exposed to the transport of anthropogenic aerosol compared to sites like Barrow and Tiksi. The average AOT values are 0.05 and 0.08 for Kangerlussuaq and Hornsund while they are 0.08 and 0.11 for Barrow and Tiksi. The AOT variabilities are also larger over Tiksi and Barrow (0.12 and 0.05) compared to those over Hornsund and Kangerlussuaq (0.04 and 0.02) due to larger impacts of advection effects. Large variability over Barrow is impacted by aerosols of accumulated background sources in the central Arctic along with long-range transport of biomass burning from North America/Europe and dust from Asia [63]. Over southern Moscow and the Ural Mountains, shipping emissions and gas flaring from possible offshore mining activities contribute to large variabilities over Tiksi [65]. Seasonal AOT patterns for the selected sites are higher in spring and lower in summer/autumn, which is consistent with the Arctic haze temporal features that are expected to be more pronounced in spring and early summer. The AOTs over Barrow and Tiksi during the summer and autumn months become smaller due

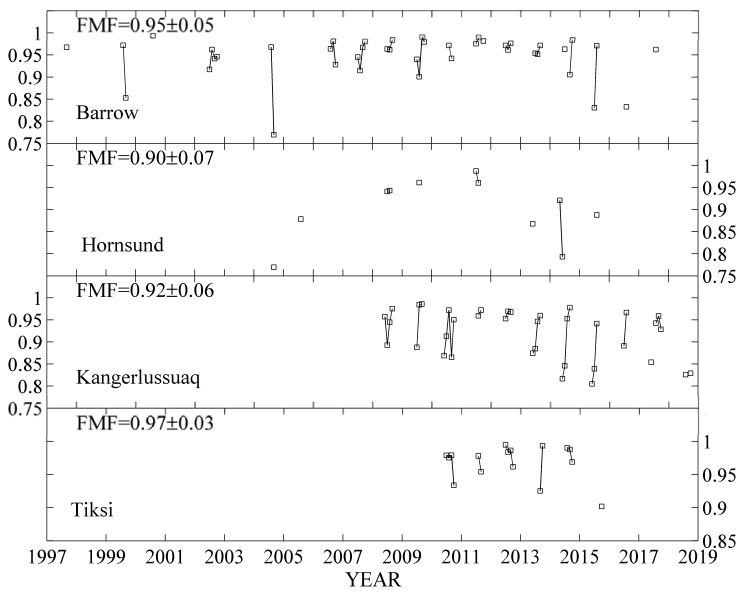

Fig. 3. Same as Fig. 2 but for FMF.

to enhanced precipitation, thus increased wet deposition of aerosol particles in the Arctic Basin [32]. AOTs during the spring period over Kangerlussuaq are around 0.07-0.1 and decrease to less than 0.05 during summertime, which can be used as the background cases in the Arctic regions.

Fig. 3 shows the corresponding patterns of FMF for those four sites. Please note, due to a stricter selection criterion of FMF retrieval compared to AOT retrieval in AERONET products [44], much less observations of FMF are available compared to AOT. All four sites show that the fine-mode aerosol dominate (FMFs larger than 0.9). Barrow and Tiksi provide larger FMFs compared to Horsund and Kangerlussuaq, further indicating larger anthropogenic contributions. No consistent annual trend of FMF over Barrow is observed. However, relatively smaller FMF (coarse-mode particles) appears more frequently during summer due to the increase of the evaporation and wind-driven sea salt aerosols, which is most likely linked to the sea ice retreat during each summer and the change of wind properties [63]. Extremely small FMFs $(<0.85)$ are observed during the summer period over Barrow. FMF over Tiksi is larger in spring and becomes smaller in the summer period because anthropogenic pollution is an important source in spring, and the contribution of biogenic emissions is significant in summer [66]. FMFs over Kangerlussuaq are in general smaller (around 0.9 or less), especially during summer and larger during spring (above 0.95).

According to the above analysis, the Kangerlussuaq Greenland site can be used as a representative site for Arctic aerosol. At the same time, Greenland is the largest snow/icecovered area over the Arctic regions. In Section IV, we will thus use all the observations over Kangerlussuaq to further investigate the Arctic aerosol properties and their effects on satellite remote sensing of AOT over the Arctic snow/icecovered regions. Fig. 4 shows the monthly AOT climatology over Kangerlussuaq. Relatively larger AOTs during spring and smaller AOTs during summer are seen. The month with the largest AOT (April) is chosen as the representative month for Arctic haze while the two months with the smallest AOT (August and September) are chosen to investigate the Arctic background cases. 


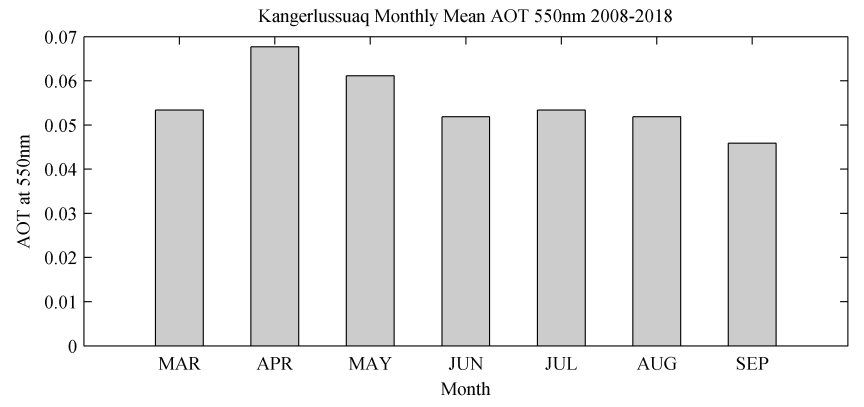

Fig. 4. Monthly AOT climatology over Kangerlussuaq.
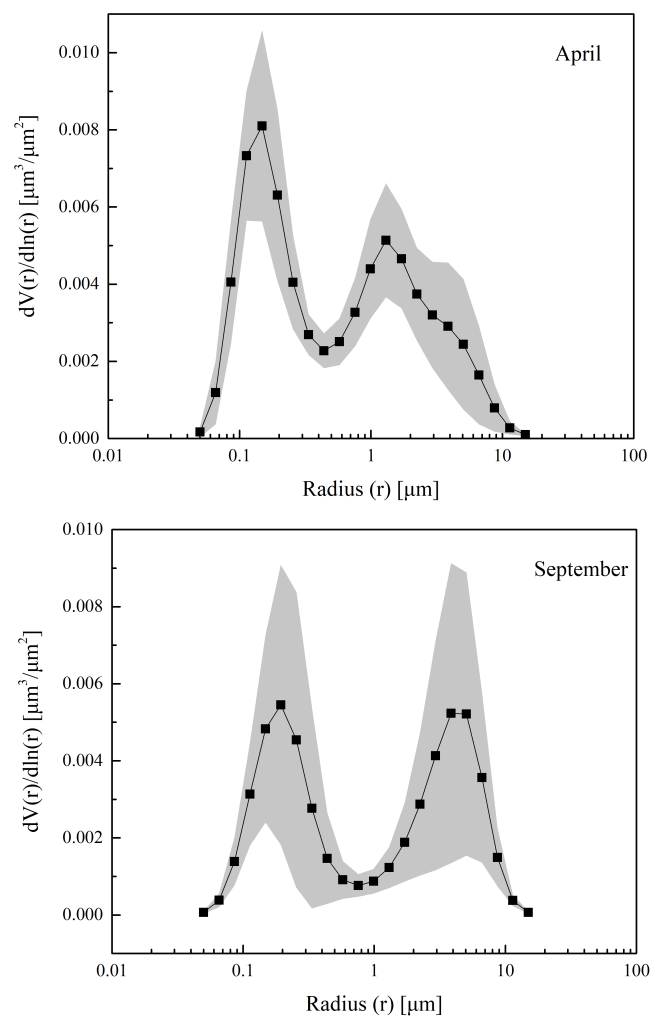

Fig. 5. Monthly PSD climatology over Kangerlussuaq for (Top) April and (Bottom) September. The black dots are the AEROENT bins, and the gray shaded area indicates the variability.

\section{B. PSD and RI}

PSD and RI over the Kangerlussuaq site are selected to characterize the Arctic aerosol types (background and Arctic haze). Fig. 5 shows the PSD climatology over Kangerlussuaq for April (haze month) and September (clean month). The monthly mean volume PSD climatology has been calculated using the monthly mean volume PSD provided by AERONET. The black points are PSDs for 22 logarithmically equidistant discrete points. The gray areas are the $\pm \sigma$, indicating the variability. According to Fig. 5, both months exhibit a bimodal distribution. As expected, the haze month shows a more distinct fine mode compared to the clear month. The particle size peaks of both fine mode $\left(r_{\text {fine }}=0.148 \mu \mathrm{m}\right)$ and coarse mode $\left(r_{\text {coarse }}=1.302 \mu \mathrm{m}\right)$ for April are smaller compared to September $\left(r_{\text {fine }}=0.194 \mu \mathrm{m}\right.$ and $\left.r_{\text {coarse }}=3.857 \mu \mathrm{m}\right)$,
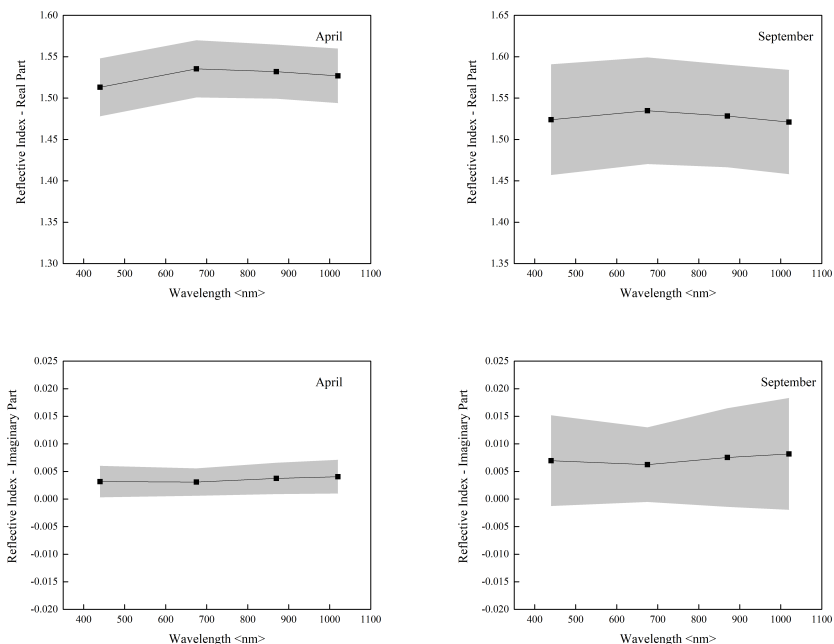

Fig. 6. Same as Fig. 5 but for RI. (Top) Real part of the RI. (Bottom) Imaginary part of the RI for both selected months: for (Left) April and (Right) September.

indicating a larger contribution of fine particles, which agrees with the previous analysis. Fig. 6 shows the RI of the corresponding months. The real part of RI for both haze and clear months are between 1.51 and 1.53 , and both show similar wavelength-dependent features. The imaginary part of RI for April is much smaller compared to September. The ranges of imaginary parts for different wavelengths are $[0.03,0.04]$ and $[0.06,0.08]$ for April and September, respectively, indicating larger aerosol absorption during the haze month compared to the clean month.

The PSD and RI features for haze and clean cases, the monthly PSD climatology over Kangerlussuaq for August (representing a clear month), and a strong event (AOT is around 0.3) during August 25, 2017, are also analyzed. Both PSD and RI show similar patterns of fine-mode aerosol domination compared to those of April and September. However, the contribution of coarse mode differs depending on time and location. In the following section, PSDs and RIs for all four stations will be used in the forward simulations to understand the impact of satellite remote sensing of aerosol properties over the Arctic regions.

\section{Retrieval Algorithm}

\section{A. Theoretical Background of Retrieval Algorithm}

The TOA reflection function depends on several atmospheric and surface parameters [42]. For cloud-free conditions and in the absence of strong gaseous absorption, there are aerosol loading and surface reflection [45]. We assume that aerosol loading can be described by the aerosol type (PSD and RI) and aerosol particle number density, i.e., the number of aerosol particles per unit volume $N(z)$ at the altitude $z$. The surface reflectance will be described by a selected bidirectional reflectance distribution function (BRDF) model.

The snow BRDF selected is the parameterization known as Ross-Li linear kernel model [67]. In this case, the surface 
reflectance is given in a most general form as follows:

$$
R_{s}(\lambda, \Omega)=\sum_{i=1}^{3} k_{i}(\lambda) K_{i}(\Omega)
$$

where $R_{s}(\lambda, \Omega)$ is the bidirectional surface reflection function, $K_{2}(\Omega)$ and $K_{3}(\Omega)$ represent the volume scattering and geometric-optic terms (or kernels), respectively. $K_{1}=1$, $k_{1}(\lambda), k_{2}(\lambda)$, and $k_{3}(\lambda)$ are the input parameters, $\lambda$ is the wavelength, $\Omega$ comprises the solar zenith angle, relative azimuth angle, and observation zenith angle.

The TOA reflection function is given by [75]

$$
R(\lambda, \Omega)=F\left[\Omega ; k_{1}(\lambda), k_{2}(\lambda), k_{3}(\lambda), N(z)\right]
$$

where the operator $\mathrm{F}$ represents a radiative transfer model that provides a relationship between optical characteristics of the atmosphere underlying surface and TOA reflection function. We note that the operator $\mathrm{F}$ can also be referred to as a forward function [75]. From a mathematical point of view, the reflection function is, at a selected wavelength, a nonlinear function of the parameters $k_{1}, k_{2}, k_{3}$, and a nonlinear functional of $N(z)$.

Under these assumptions, the variation of the spectral reflectance $R(\lambda, \Omega)$ with respect to the variation $\Delta k_{i}$ of the coefficients $k_{i}$ and the variation $\delta N(z)$ of the aerosol particle number density $N(z)$ can be written in the form of the Taylor series

$$
\begin{aligned}
\Delta R(\lambda, \Omega)=\int_{0}^{H} W_{N}(z, \lambda, \Omega) \delta N & \\
& +\sum_{i=1}^{3} W_{i}(\lambda, \Omega) \Delta k_{i}(\lambda)
\end{aligned}
$$

where we neglected nonlinear terms and

$$
W_{i}(\lambda, \Omega)=\frac{\partial R(\lambda, \Omega)}{\partial k_{i}(\lambda)}, \quad W_{N}(z, \lambda, \Omega)=\frac{\delta R(\lambda, \Omega)}{\delta N(z)}
$$

are the partial derivative and functional derivative of $R(\lambda, \Omega)$ with respect to the parameter $k_{i}(\lambda)$ and function $N(z)$, respectively. We note that $W_{i}$ and $W_{N}$ are usually called weighting functions [76].

We assume that the variation of the vertical profile of aerosol number density can be described by scaling the a priori known profile $N(z)$, i.e., $N^{\prime}(z)=C_{N} N(z)$. In this case

$$
\frac{\delta N(z)}{N(z)}=\frac{N^{\prime}(z)-N(z)}{N(z)}=C_{N}-1 .
$$

Substituting this expression into (7), we have

$$
\begin{aligned}
\Delta R(\lambda, \Omega)=x_{N} \int_{0}^{H} W_{N}(z, \lambda, \Omega) & N(z) d z \\
& +\sum_{i=1}^{3} W_{i}(\lambda, \Omega) \Delta k_{i}(\lambda)
\end{aligned}
$$

where $x_{N}=C_{N}-1$.

It is reasonable to introduce the variation of AOT instead of parameter $x_{N}$. To do this, we write AOT as follows:

$$
\tau=\int_{0}^{H} N(z) \sigma_{e}(z) d z
$$

where $\sigma_{e}(z)$ is the extinction cross section of aerosol particles at the reference wavelength. The variation of AOT is then given by

$$
\Delta \tau=\int_{0}^{H} \delta N(z) \sigma_{e}(z) d z=x_{N} \int_{0}^{H} N(z) \sigma_{e}(z) d z=x_{N} \tau .
$$

Introducing the weighting function for the absolute variation of AOT as follows:

$$
W_{\tau}(\lambda, \Omega)=\frac{1}{\tau} \int_{0}^{H} W_{N}(z, \lambda, \Omega) d z
$$

we have

$$
\Delta R(\lambda, \Omega)=W_{\tau}(\lambda, \Omega) \Delta \tau+\sum_{i=1}^{3} W_{i}(\lambda, \Omega) \Delta k_{i}(\lambda) .
$$

Because the TOA reflectance measurements are performed at a discrete number of both wavelengths and observation/illumination conditions, we rewrite (14) as follows:

$$
\Delta R\left(\lambda_{j}, \Omega_{m}\right)=W_{\tau}\left(\lambda_{j}, \Omega_{m}\right) \Delta \tau+\sum_{i=1}^{3} W_{i}\left(\lambda_{j}, \Omega_{m}\right) \Delta k_{i}\left(\lambda_{j}\right)
$$

where $j=1, \ldots, L, m=1, \ldots, M$, and $L, M$ are the number of wavelengths and observation directions, respectively.

To simplify the presentation of the retrieval algorithm, let us rewrite (15) in the following equivalent form:

$$
\begin{aligned}
R\left(\lambda_{j}, \Omega_{m}\right)=\bar{R}_{0}\left(\lambda_{j}, \Omega_{m}\right)+ & W_{\tau}\left(\lambda_{j}, \Omega_{m}\right) \tau \\
& +\sum_{i=1}^{3} W_{i}\left(\lambda_{j}, \Omega_{m}\right) k_{i}\left(\lambda_{j}\right)
\end{aligned}
$$

where

$$
\begin{aligned}
\bar{R}_{0}\left(\lambda_{j}, \Omega_{m}\right)=R_{0}\left(\lambda_{j}, \Omega_{m}\right)- & W_{\tau}\left(\lambda_{j}, \Omega_{m}\right) \tau_{0} \\
& -\sum_{i=1}^{3} W_{i}\left(\lambda_{j}, \Omega_{m}\right) k_{i, 0}\left(\lambda_{j}\right) .
\end{aligned}
$$

$R_{0}\left(\lambda_{j}, \Omega_{m}\right)$ is TOA reflection function calculated using a priori values for atmospheric and surface parameters.

The resultant linear relationship is used to formulate the inverse problem with respect to AOT and coefficients, $k_{i}$, using satellite-measured TOA spectral reflectance. We restrict ourselves to $L=4$ using reflectance measurements at wavelengths 490, 565, 670, and $865 \mathrm{~nm}$ and $M=14$ observation directions for typical POLDER observation geometries.

For practical applications, it is reasonable to rewrite (16) in a vector-matrix form. To do this, we introduce the vector containing coefficients of the BRDF model

$$
\mathbf{K}_{j}=\left|k_{1}\left(\lambda_{j}\right), k_{2}\left(\lambda_{j}\right), k_{3}\left(\lambda_{j}\right)\right|^{T}
$$

with state vector

$$
X_{j}=\left|\mathbf{K}_{j}^{T}\left(\lambda_{j}\right), \tau\right|^{T}
$$

and the vector containing reflection functions for all observation directions at a selected wavelength $j$

$$
\mathbf{R}_{j}=\left|R\left(\lambda_{j}, \Omega_{1}\right), R\left(\lambda_{j}, \Omega_{2}\right), \ldots, R_{2}\left(\lambda_{j}, \Omega_{m}\right)\right|^{T}
$$


and the matrix $\boldsymbol{W}_{j, 0}$

$W_{j, 0}=\left[\begin{array}{cccc}W_{1}\left(\lambda_{j}, \Omega_{1}\right) & W_{2}\left(\lambda_{j}, \Omega_{1}\right) & W_{3}\left(\lambda_{j}, \Omega_{1}\right) & W_{\tau}\left(\lambda_{j}, \Omega_{1}\right) \\ W_{1}\left(\lambda_{j}, \Omega_{2}\right) & W_{2}\left(\lambda_{j}, \Omega_{2}\right) & W_{3}\left(\lambda_{j}, \Omega_{2}\right) & W_{\tau}\left(\lambda_{j}, \Omega_{2}\right) \\ \vdots & \vdots & \vdots & \vdots \\ W_{1}\left(\lambda_{j}, \Omega_{M}\right) & W_{2}\left(\lambda_{j}, \Omega_{M}\right) & W_{3}\left(\lambda_{j}, \Omega_{M}\right) & W_{\tau}\left(\lambda_{j}, \Omega_{M}\right)\end{array}\right]$

where $j=1,2,3,4$ and $T$ denotes the transposition. Then, (16) is written for the wavelength $\lambda_{j}$ as follows:

$$
\mathbf{R}_{j}=\overline{\mathbf{R}}_{j, 0}+\mathbf{W}_{j, 0} \mathbf{X}_{j}
$$

The components of vectors $\mathbf{R}_{j}$ and $\overline{\mathbf{R}}_{j, 0}$ are measured and simulated reflectance at the wavelengths $\lambda_{j}$ and all observation directions $\Omega_{m}$. The subscript "0" denotes that the simulated reflectance and weighting functions are calculated using state vector $\mathbf{X}_{j, 0}$.

In the first step, the algorithm solves the inverse problem with respect to the surface parameters at a wavelength of $865 \mathrm{~nm}$ where the impact of the atmosphere is minimal. Assuming that AOT is known and is equal to the a priori value, the estimation of the vector of parameters is obtained by the minimization of the following cost function:

$$
\Delta_{1}=\left\|\left(\mathbf{R}_{4}-\overline{\mathbf{R}}_{4,0}\right)-\mathbf{W}_{4,0} \mathbf{K}_{4}\right\|^{2}
$$

with the constraints

$$
K_{4,0}-\Delta K_{4} \leq K_{4} \leq K_{4,0}+\Delta K_{4}
$$

Here, $\Delta K_{4}$ is a priori variability of the BRDF model coefficients at a wavelength of $865 \mathrm{~nm}$. We note that the square root of $\Delta_{1}$ is the Euclidean distance between vectors $\left(\mathbf{R}_{4}-\overline{\mathbf{R}}_{4,0}\right)$ and $\mathbf{W}_{4,0} \mathbf{K}_{4}$.

The solution of minimization problem given by (23) and (24) is performed by the GALAHAD package (http://www.galahad.rl.ac.uk/) which uses a primal-dual interior-point trust-region method to solve the quadratic programming problem and results in the estimation of the coefficients $\hat{\mathbf{K}}_{4,0}$.

The successful solution of the formulated inverse problem requires adequate a priori information with respect to the coefficients of the surface reflection model in different spectral channels. To obtain such information, we performed statistical analysis using the POLDER-derived database presented in [69]. In particular, this database contains time-series of coefficients of the Ross-Li model over the Arctic regions. An example of our statistical analysis is shown in Fig. 7. Fig. 7 shows the 2-D density plot of coefficients $k_{1}\left(\lambda_{4}\right)$ and $k_{1}\left(\lambda_{2}\right)$ at wavelengths 865 and $565 \mathrm{~nm}$, the color indicates the number of matchups in a particular area of 2-D square space, with a size of $0.1 \times 0.1$. Fig. 7 demonstrates a high correlation $\left(R^{2}=0.954\right)$ between coefficients $k_{1}$ at these wavelengths. Please note here that we use $R^{2}$ in the whole article, which is the coefficient of determination. For simplification, we still call it a correlation coefficient in the whole article. The linear regression equation, that is

$$
k_{1}\left(\lambda_{2}\right)=a_{1,2} k_{1}\left(\lambda_{4}\right)+b_{1,2}
$$

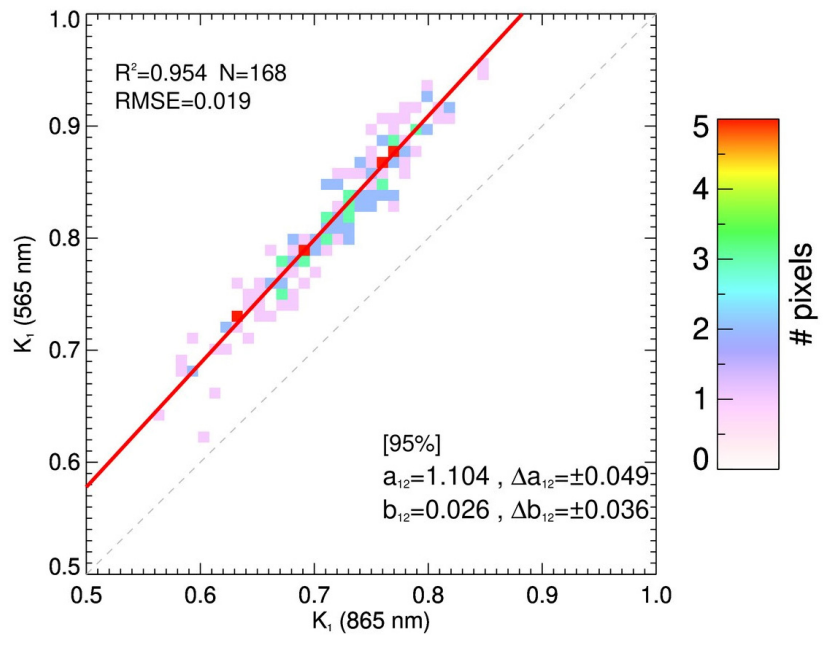

Fig. 7. Density plot of coefficients $k_{1}$ at wavelengths 865 and $565 \mathrm{~nm}$. Regression equation is given within $95 \%$ confidence interval. $R^{2}$ and $N$ are correlation coefficient and the number of samples, respectively. RMSE is calculated between prediction of $k_{1}$ at $565 \mathrm{~nm}$ using the regression equation and the PARASOL-derived $k_{1}$ at $565 \mathrm{~nm}$. Red solid line and black dashed line are regression line and 1:1 line, respectively.

with the slope $a_{1,2}$, and intercept $b_{1,2}$, and their uncertainties, $\Delta a_{1,2}$ and $\Delta b_{1,2}$, within a $95 \%$ confidence interval are shown in Fig. 7. RMSE is calculated between the prediction of $k_{1}$ at $565 \mathrm{~nm}$ using the regression equation and the PARASOLderived $k_{1}$ at this wavelength. Similar regression equations have been obtained for $k_{1}\left(\lambda_{4}\right), k_{1}\left(\lambda_{1}\right), k_{1}\left(\lambda_{4}\right)$, and $k_{1}\left(\lambda_{3}\right)$, as well as for coefficients $k_{2}$ and $k_{3}$.

According to this statistical analysis, the linear regression relationship between Ross-Li coefficients at the wavelengths $\lambda_{j}$ and $\lambda_{4}$ was obtained as follows:

$$
\begin{aligned}
& \hat{k}_{1,0}\left(\lambda_{j}\right)=a_{1, j} \hat{k}_{1,0}\left(\lambda_{4}\right)+b_{1, j} \\
& \hat{k}_{2,0}\left(\lambda_{j}\right)=a_{2, j} \hat{k}_{2,0}\left(\lambda_{4}\right)+b_{2, j} \\
& \hat{k}_{3,0}\left(\lambda_{j}\right)=a_{3, j} \hat{k}_{3,0}\left(\lambda_{4}\right)+b_{3, j}
\end{aligned}
$$

where $\hat{k}_{1,0}\left(\lambda_{4}\right), \hat{k}_{2,0}\left(\lambda_{4}\right)$, and $\hat{k}_{3,0}\left(\lambda_{4}\right)$ are elements of the vector, and $\hat{K}_{4,0}$, and $a_{1, j}, a_{2, j}, a_{3, j}$ and $b_{1, j}, b_{2, j}, b_{3, j}$ are slopes and intercepts, respectively, at the wavelength $\lambda_{j}, j=1,2,3$. These equations can be rewritten in a more compact vectormatrix form as follows:

$$
\hat{\mathbf{K}}_{j, 0}=\mathbf{A}_{j} \hat{\mathbf{K}}_{4,0}+\mathbf{B}_{j}, \quad j=1,2,3 .
$$

Here, $\mathbf{A}_{j}$ is a diagonal matrix with diagonal elements of slopes $a_{1, j}, a_{2, j}, a_{3, j}$ and $\mathbf{B}_{j}$ is the column-vector with components of intercepts $b_{1, j}, b_{2, j}$, and $b_{3, j}$.

By using the above equation (29), one can assess the uncertainty in the coefficients as follows:

$$
\Delta \hat{\mathbf{K}}_{j, 0}=\Delta \mathbf{A}_{j} \hat{\mathbf{K}}_{4,0}+\Delta \mathbf{B}_{j}, \quad j=1,2,3 .
$$

Although the linear regression model given by (29) enables us to estimate coefficients of the surface reflectance $K_{j}$ at all short wavelengths $(j=1,2,3)$, we do not use them as retrieval results due to the large uncertainties caused by the statistical variabilities. In addition, a priori information provided by the 
linear regression model is used in the next step of the retrieval process.

The second step of the retrieval algorithm solves the inverse problem at all wavelengths with respect to the state vector $\mathbf{X}=\left|K_{1}^{T}, K_{2}^{T}, K_{3}^{T}, K_{4}^{T}, \tau\right|^{T}$. The estimation of the state vector is obtained at this step by the minimization of the following cost function:

$$
\Delta_{2}=\left\|\left(\mathbf{R}-\overline{\boldsymbol{R}}_{0}\right)-\mathbf{W}_{0} \mathbf{X}\right\|^{2}
$$

under the following linear constraints:

$$
\begin{aligned}
\hat{K}_{j, 0}-\Delta \hat{K}_{j, 0} & \leq K_{j} \leq \hat{K}_{j, 0}+\Delta \hat{K}_{j, 0}, \quad j=1,2,3 \\
K_{4}^{l} & \leq K_{4} \leq K_{4}^{u} \\
\tau^{l} & \leq \tau \leq \tau^{u}
\end{aligned}
$$

where $\hat{K}_{j, 0}$ and $\Delta \hat{K}_{j, 0}$ are given by (29) and (30), respectively, and $\tau^{l}, \tau^{u}, K_{4}^{l}, K_{4}^{u}$ are bounds for AOT and Ross-Li coefficients at $865 \mathrm{~nm}$.

The solution of the minimization problem given by (23) and (31) with respect to the state vector $\mathbf{X}_{1}$ is affected by linearization error ignored during the derivation of (16). In order to mitigate the impacts of linearization errors, we solve the minimization problems given by (23) and (31) iteratively. In particular, vector $\mathbf{X}_{1}$, instead of vector $\mathbf{X}_{0}$, is used in the next iteration to perform a calculation of simulated reflectance and weighting functions. The iteration process finishes when the difference between $\mathbf{X}_{n}$ and $\mathbf{X}_{n-1}$ is less than the preselected criteria.

\section{B. Surface Parameterization}

The accurate description of the surface reflection is an important issue in order to retrieve AOT using satellitemeasured TOA reflectance. For the surfaces covered by snow in the Arctic, parameterization of snow reflection is especially important because a small variation of snow properties can lead to the larger variation of TOA reflection, which further introduces larger uncertainties to decouple aerosol from surface contribution.

Recently, a three-parametric surface BRDF model known as Ross-Li linear kernel model [67] was extended by an additional "snow" kernel [68]. In this case, the snow reflection is given as follows:

$$
R_{s}(\lambda, \Omega)=\sum_{i=1}^{4} k_{i}(\lambda) K_{i}(\Omega)
$$

where the fourth term describes the contribution of the snow kernel and other terms are the same as in (5).

The parameterization using (35) shows an improvement of accuracy, in particular, at glint observation geometries, to retrieve snow reflection measured by the POLDER instrument [68]. However, attempts to use this four-parametric snow reflection model to retrieve both AOT and surface parameters simultaneously result in an instability caused by the correlation between the weighting function of AOT and weighting functions of surface parameters. This correlation is significantly weaker using the three-parametric Ross-Li linear kernel model, i.e., excluding additional "snow" kernel.
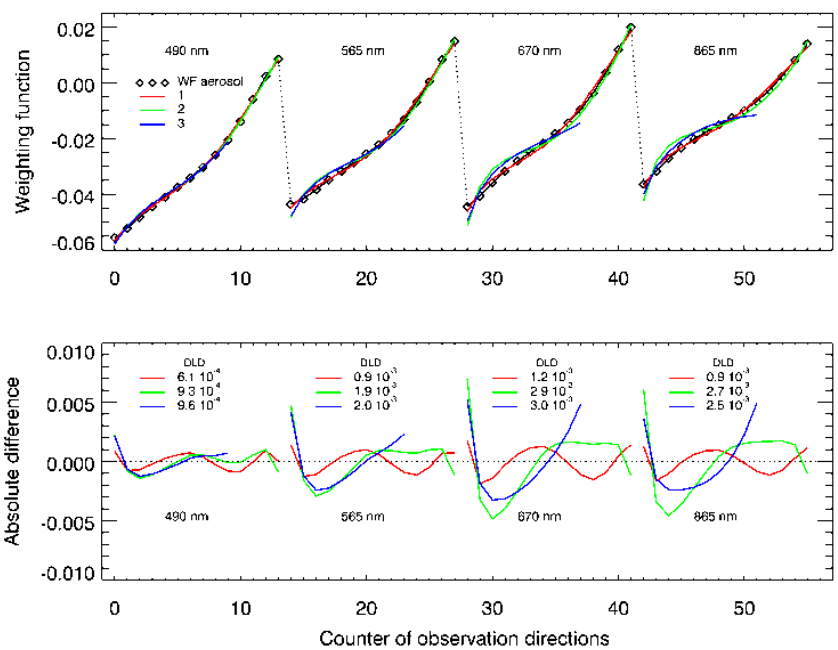

Fig. 8. (Top) Symbols depict the aerosol weighting function, $W_{\tau}$; red and green lines represent the approximation, $\hat{W}_{\tau}$, obtained using four-parametric and three-parametric BRDF models, respectively; blue lines demonstrate the approximation at the observation angles outside of glint direction. (Bottom) Red, green, and blue lines depict the difference $W_{\tau}-\hat{W}_{\tau}$ obtained for fourparametric, three-parametric, and three-parametric outside the glint direction BRDF model, respectively; DLD is calculated according to (38).

In order to investigate this relationship quantitatively, we consider the linear combination of AOT and surface parameters weighting functions $W_{\tau}$ and $\left\{W_{1}, \ldots, W_{4}\right\}$, respectively. Please note that the system of vectors $\left\{W_{\tau}, W_{1}, \ldots, W_{4}\right\}$ is linearly dependent if one of the vectors can be represented as a linear combination of all other

$$
W_{\tau}\left(\lambda_{j}\right)=\sum_{i=1}^{4} c_{i} W_{i}\left(\lambda_{j}\right)
$$

where $\lambda_{j}$ are discrete wavelengths. The coefficients, $c_{i}$, which provide the best approximation of the vector, $\mathbf{W}_{\tau}$, can be obtained by solving the following minimization problem:

$$
\left\|\mathbf{W}_{\tau}-\sum_{i=1}^{4} c_{i} \mathbf{W}_{i}\right\|^{2} \rightarrow \min
$$

where for simplification, the argument, $\lambda_{j}$ is omitted.

The degree of linear dependence (DLD) can be quantitatively described as follows:

$$
Q_{p}=\sqrt{\frac{1}{M} \sum_{m=1}^{M}\left(w_{\tau, m}-\hat{w}_{\tau, m}\right)^{2}}
$$

where $w_{\tau, m}$ and $\hat{w}_{\tau, m}$ are components of vectors $W_{\tau}$ and $\hat{W}_{\tau}$, respectively, $\hat{W}_{\tau}=\sum_{i=1}^{4} \hat{c}_{i} W_{i}$, and coefficients $\hat{c}_{i}$ are the solution of the minimization problem given by (37).

The DLD was calculated for both four- and three-parametric Ross-Li linear kernel models, which will be referred to as $Q_{4}$ and $Q_{3}$, respectively. The weighting functions were calculated for a typical POLDER instrument observation/illumination geometry $(M=14)$ at the wavelengths $490,565,670$, and $865 \mathrm{~nm}$. The aerosol type was selected to be weakly absorbing (WA) and the AOT was set to 0.2 . 
Fig. 8 (top) represents aerosol weighting function (symbols) at the four above-mentioned wavelengths and the approximations obtained using a four-parametric and three-parametric BRDF model (given by red and green lines, respectively). Fig. 8 (bottom) shows the difference, $W_{\tau}-\hat{W}_{\tau}$, and DLD calculated for four- and three-parametric BRDF models.

Fig. 8 (bottom) shows that the DLD is larger at shorter wavelengths because the increase of multiple scattering processes with the decrease of wavelength leads to a larger impact of atmosphere on the angular structure of surface reflection. In particular, $Q_{4}$ at $565 \mathrm{~nm}$ is about $50 \%$ larger than $Q_{4}$ at $490 \mathrm{~nm}$. It can also be seen that the DLD derived by the three-parametric BRDF model is 2-3 times larger than that from the four-parametric model. Indeed, according to Fig. 8 (bottom), DLD for the three-parametric BRDF model is $Q_{3}=2.9 \times 10^{-3}$ whereas $Q_{4}=1.2 \times 10^{-3}$ at a wavelength of $670 \mathrm{~nm}$.

Thus, employing a four-parametric BRDF model leads to a significant increase of the correlation between the weighting functions involved in the retrieval process. Therefore, in the retrieval algorithm, we use the three-parametric BRDF model known as Ross-Li linear kernel model. In order to mitigate the loss of accuracy caused by employing the three-parametric model instead of the four-parametric one, we exclude the observation angles in the glint range in the retrieval process. Fig. 8 (blue lines) shows the angular-dependent patterns of DLD by excluding the glint range. One can see that the decrease of observation directions from 14 angles to 9 does not lead to increasing of linear dependencies and thus does not increase the correlation between AOT and parameters of the surface reflection model.

\section{Impacts of Arctic Aerosol Typing and Surface Model on the Retrieval of AOT AND PARAMETERS OF Surface Reflection Model-Sensitivity Study}

Besides the surface reflection parameters mentioned above, the state vector of the formulated inverse problem includes a single parameter-AOT. However, AOT describes aerosol loading only without information related to the aerosol microphysical properties such as PSD function and real and imaginary parts of the RI. Therefore, the PSD function and RI, which are the main characteristics of a given aerosol type, should be selected according to a priori information and thus can affect the retrieval accuracy of AOT and surface reflection parameters.

In order to estimate the impact of the aerosol type on the retrieval accuracy of AOT, we have performed studies using simulated TOA reflectance spectra under different typical Arctic scenarios.

\section{A. Simulation of TOA Reflectance Spectra}

The following scenarios for the surface, atmosphere, and aerosol system were selected to perform forward simulations.

1) TOA altitude was set to $60 \mathrm{~km}$;

2) Vertical profiles of the temperature, pressure, and gaseous absorber $\left(\mathrm{O}_{3}, \mathrm{NO}_{2}\right)$ were set according to the

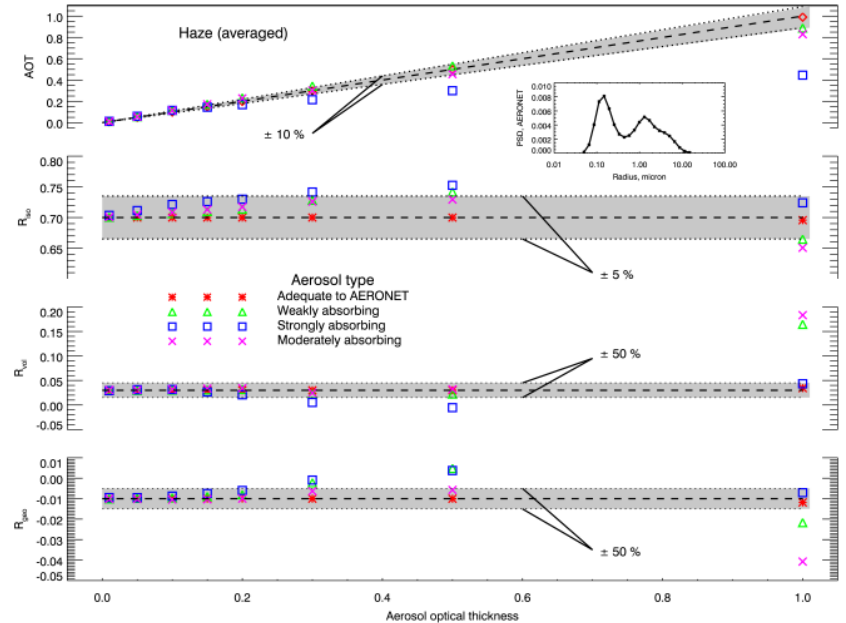

Fig. 9. (From top to bottom) Retrieval results of AOT, $R_{\text {iso }}, R_{\mathrm{vol}}$, and $R_{\text {geo }}$ obtained using adequate, WA, MA, and SA aerosol types for haze condition using predefined AOT values as shown in the $x$-axis. (Top right) Correct PSD function. The gray shaded areas represent the range where retrieved parameters differ from true ones less than $10 \%$ for AOT, less than $5 \%$ for $R_{\text {iso }}$, and less than $50 \%$ for $R_{\text {vol }}$ and $R_{\text {geo }}$.

database of the Bremen 2-D chemical transport model [70].

3) Surface reflection was described by the three-parametric Ross-Li linear kernel model [67].

4) Four aerosol types typical for the clean and haze conditions in the Arctic were selected according to AERONET data measurements over Greenland (see Section III).

5) Aerosol loading was changed by scaling the vertical profile of aerosol particles' number density to provide an AOT equal to $[0.01,0.05,0.1,0.15,0.2,0.3,0.5$, $1.0]$.

The radiative transfer calculations were performed by the software package SCIATRAN [71], setting the solar zenith angles and viewing directions corresponding to one of the selected POLDER observation geometries over Greenland for four wavelengths $490,565,670$, and 865 . Using the above-formulated scenarios, we calculated 32 TOA reflectance spectra (four aerosol types and eight AOTs) which will be considered below as measured vector $\mathbf{R}$ in (31).

\section{B. Solution of Inverse Problem}

Employing the algorithm described in Section IV, the inverse problem with respect to AOT and surface parameters was solved separately for each of the 32 TOA reflectance spectra simulated above. Moreover, for each scenario, the inverse problem was solved four times using different aerosol types: adequate (the same as in forward simulation), WA, moderately absorbing (MA), and strongly absorbing (SA). The WA, MA, and SA aerosol types were adapted from MODIS collection 6 and utilized in the XBAER algorithm [39]. This enables the impact of aerosol type on the retrieved AOT to be investigated.

The retrieval results are shown in Figs. 9-12. The structure of Figs. $9-12$ is similar and consists of four main parts: 


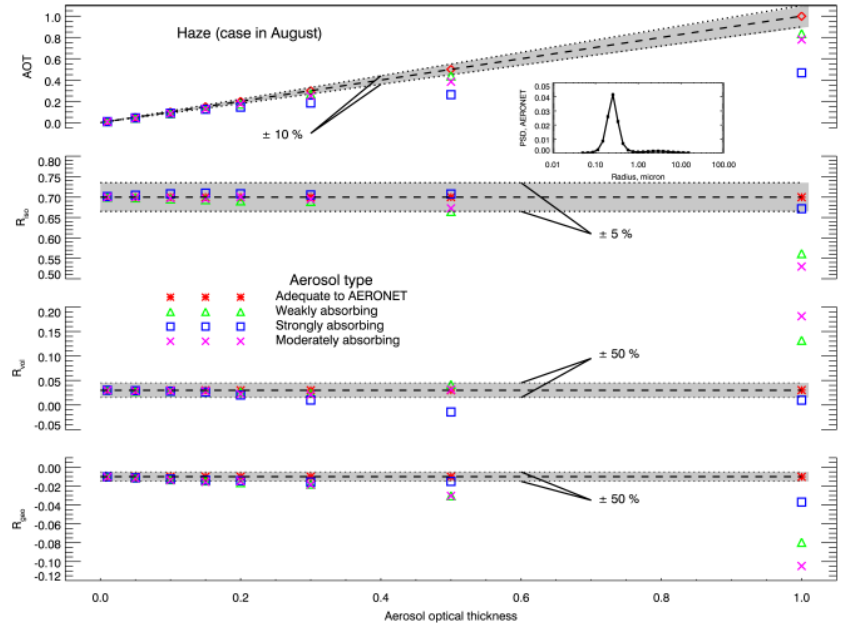

Fig. 10. Same as Fig. 9 but for a haze case on August 25.

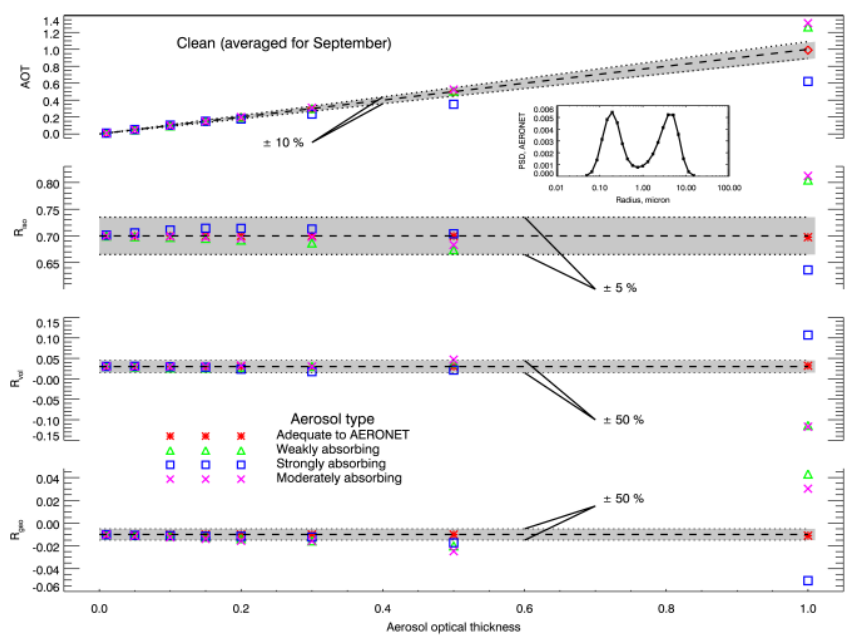

Fig. 11. (From top to bottom)Retrieval results of AOT, $R_{\text {iso }}, R_{\mathrm{vol}}$, and $R_{\text {geo }}$ obtained using adequate, WA, MA, and SA aerosol type for clean condition using predefined AOT values as shown in the $x$-axis. (Top right) Correct PSD function. The gray shaded areas have the same meaning as in Fig. 9.

top one presents the retrieval results for AOT; second, third, and fourth ones show retrieval results for parameters $k_{1}\left(\lambda_{4}\right)$, $k_{2}\left(\lambda_{4}\right)$, and $k_{3}\left(\lambda_{4}\right)$ at the wavelength $\lambda_{4}=865 \mathrm{~nm}$. Note that, for simplicity, we refer to in the rest of this section to these parameters as $R_{\text {iso }}, R_{\mathrm{vol}}$, and $R_{\mathrm{geo}}$. The gray shaded areas represent the range around true values of the parameter where retrieved parameters differ from the true ones less than $10 \%$ for AOT, less than $5 \%$ for $R_{\mathrm{iso}}$, and less than $50 \%$ for $R_{\mathrm{vol}}$ and $R_{\text {geo }}$. The small plot on the right-hand side of the top one demonstrates the PSD function (dV/dln r) used in the forward simulations.

\section{Results for Haze Conditions}

Figs. 9 and 10 depict retrieval results for the haze conditions. These conditions were selected according to the criteria that AOT measured by AERONET stations in Greenland is around 0.3. The climatological PSD function for April is given in

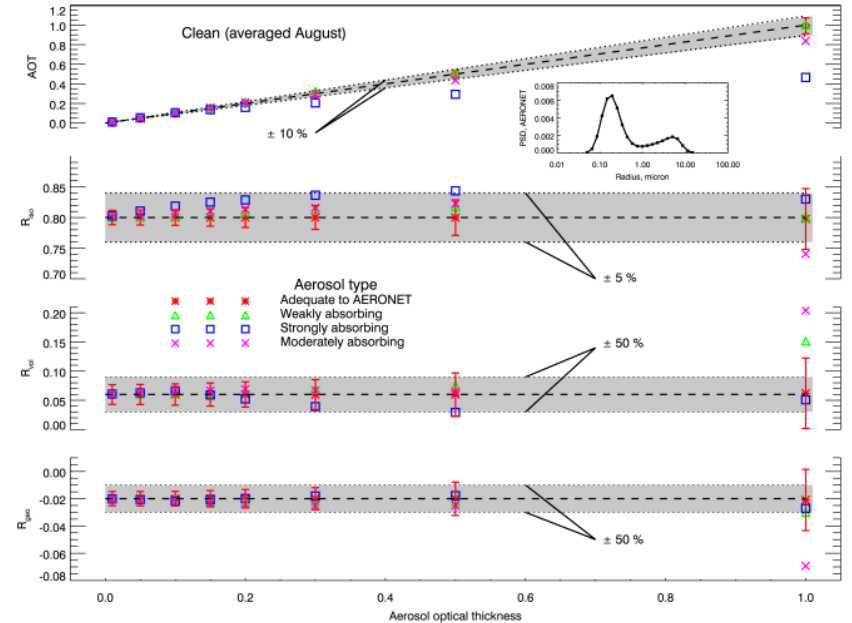

Fig. 12. Same as in Fig. 11 but for clean conditions in August. Additionally, the error bars show $\pm \sigma_{i}$ deviation from the sample mean which are given by red stars.

Fig. 9 (top). It can be seen that averaged PSD demonstrates bimodal distribution with the position of the maximum of the fine and coarse modes at about 0.15 and $1.4 \mu \mathrm{m}$, respectively. In order to account for the high variability of the PSD function, we have also selected a single PSD function measured on August 25, 2017, by AERONET station over Greenland. The measured AOT was about 0.3. The PSD function for August 25, 2017, is given in Fig. 10 (top). It follows that the contribution of coarse particles is significantly smaller than in the case of averaged PSD and the maximum concentration of the fine mode is shifted to about $0.24 \mu \mathrm{m}$, which agrees with results presented by Stock et al. [72].

The retrieval results obtained using the adequate aerosol type in the retrieval process are shown in Figs. 9 and 10 by red stars. High retrieval accuracy, in this case, demonstrates the correct implementation of the retrieval algorithm and asmall impact of numerical errors. Retrieval results obtained using inadequate aerosol type are presented by other symbols. Fig. 9 shows that the AOT retrieval accuracy is better than about $16 \%$ for the AOTs in the range of [0.2-1] using WA or MA aerosol type in the retrieval process instead of the correct one. Fig. 10 demonstrates that, although the PSD for the single haze case in August significantly differs from averaged PSD, usage of WA aerosol type leads to the retrieval error of less than $16 \%$ for the AOTs in the range of [0.1-1.0]. However, the usage of MA aerosol type leads in this case to the maximal retrieval error of about $23 \%$ at $\mathrm{AOT}=0.5$. The usage of SA aerosol type results for both cases in significantly larger retrieval errors, which increase up to $55 \%$ at $\mathrm{AOT}=1$. Although the main parameter in the considered retrieval algorithm is AOT, the retrieval results for the surface reflection parameters are also briefly discussed because it can help us to better understand the uncertainties in the retrieved AOT. The retrieval algorithm demonstrates a good performance with respect to the parameter $R_{\text {iso }}$. In particular, according to Figs. 9 and 10, the retrieval accuracy of $R_{\text {iso }}$ is about $5 \%$ for both WA and MA aerosol types. The retrieval 
accuracy decreases with the increase of AOT and can reach about $18 \%$ for $R_{\text {iso }}$ at AOT $=1$ for the haze case in April (see the second one in Fig. 10). The decrease of retrieval accuracy by the increase of AOT is expected because the increase of aerosol loading leads to the increase of multiple scattering processes in the atmosphere and decreases the sensitivity of TOA reflectance with respect to the variation of the surface reflectance.

The relative retrieval errors of parameters $R_{\mathrm{vol}}$ and $R_{\mathrm{geo}}$ are significantly larger as compared to $R_{\text {iso }}$. It is due to the fact that the true values of $R_{\mathrm{vol}}$ and $R_{\mathrm{geo}}$ are one order smaller than parameter $R_{\text {iso }}$.

\section{Results for Clean Conditions}

Figs. 11 and 12 demonstrate retrieval results for Arctic clean conditions. For this purpose, we used the climatological PSD function for September and August as described in Section III. Fig. 11 (top) shows that the climatological PSD for September has a bimodal distribution with the peak of radius for the fine and coarse mode are about 0.2 and $4 \mu \mathrm{m}$, respectively. Fig. 11 indicates that the AOT retrieval accuracy is better than $5 \%$ for AOT in the range of [0.01-0.2] with both WA and MA aerosol types. The accuracy decreases for an AOT larger than 0.5.

The retrieval results for AOT are presented in Fig. 12 (top) for August. PSD for September and August [see Figs. 11 and 12 (top)] are very similar. The contribution from the coarse mode in September is larger than that in August. Fig. 12 (top) demonstrates that the retrieval accuracy of AOT is better than $\sim 7.5 \%$ in the range of AOT [0.01-0.2] for both WA and MA aerosol types. As in the case of haze conditions, using SA aerosol type leads to a significant loss of retrieval accuracy.

We note that AOT retrieval accuracy is similar for clean conditions in September and August although the simulated TOA reflectance for August has been calculated for the case of brighter surface reflectance (compare surface parameters in Figs. 10 and 11).

In the case of the clean conditions (AOT in the range [0.01$0.2])$ the retrieval algorithm demonstrates a good performance with respect to parameters $R_{\mathrm{iso}}, R_{\mathrm{vol}}$, and $R_{\mathrm{geo}}$. In particular, one can see from Figs. 10 and 11 that the retrieval accuracy of $R_{\text {iso }}$ is better than $\sim 3 \%$ and depends only slightly on the selected aerosol type.

\section{E. Impact of Random Errors}

Since the random error always exists in satellite observations, we consider the impact of random measurement errors on the precision of retrieval results. In order to estimate the impact of random errors, the simulated TOA reflectance was represented as follows:

$$
\tilde{R}\left(\lambda_{j}, \Omega_{m}\right)=R\left(\lambda_{j}, \Omega_{m}\right)+\varepsilon\left(\lambda_{j}, \Omega_{m}\right)
$$

where $R\left(\lambda_{j}, \Omega_{m}\right)$ is the error-free TOA reflectance, $\varepsilon\left(\lambda_{j}, \Omega_{m}\right)$ is the random error. The random error was calculated according to the following expression:

$$
\varepsilon\left(\lambda_{j}, \Omega_{m}\right)=\frac{R\left(\lambda_{j}, \Omega_{m}\right)}{\mathrm{SNR}} \xi_{j, m}
$$

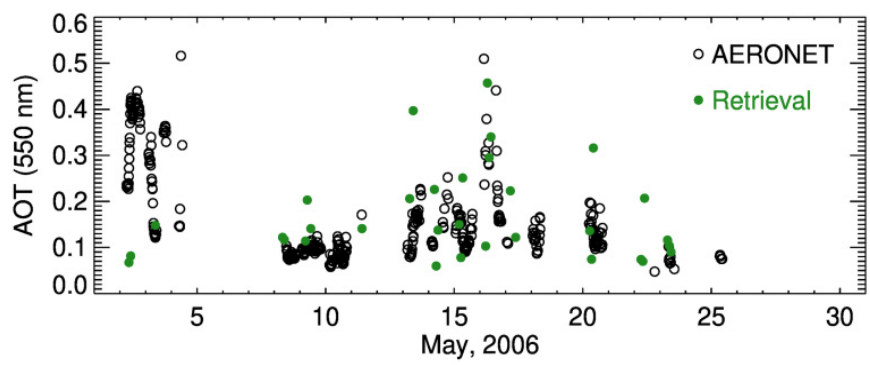

Fig. 13. Comparison between first POLDER-derived AOT (green dots) and AERONET-observed AOT (black dots).

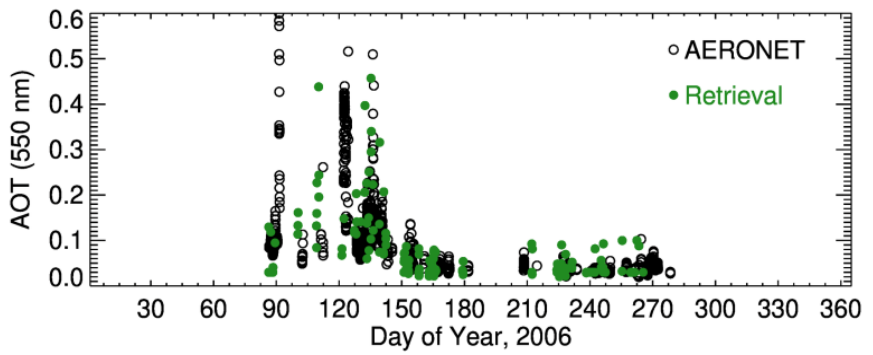

Fig. 14. Same as Fig. 13, but for the whole year of 2006 .

where SNR is the signal-to-noise ratio, which was set to be 200. SNR $=200$ is typical for the POLDER instrument and $\xi_{j, m}$ is a random value obtained using a generator of the Gaussian noise with zero mean and unit variance.

Solving the inverse problem $N$ times for different realizations of the random variable, $\xi_{j, m}$, we obtain the sequence of state vector estimations. For each component of the state vector $\boldsymbol{X}$, we calculated the sample mean and standard deviation as follows:

$$
\bar{x}_{i}=\frac{1}{N} \sum_{n=1}^{N} x_{n, i}, \quad \sigma_{i}=\sqrt{\frac{1}{N-1} \sum_{n=1}^{N}\left(x_{n, i}-\bar{x}_{i}\right)^{2}}
$$

where $N$ was set to 100 , and $x_{n, i}$ is the $i$ th component of the state vector obtained by solving the inverse problem with $n$th realization of random noise. The precision of retrieval results is shown in Fig. 12 by the error bars which show $\pm \sigma_{i}$ deviation from the sample mean which are given by red stars. As expected, we do not see any systematic deviations. However, the presented results demonstrate the increase of relative AOT retrieval error with the decrease of AOT value. In particular, the retrieval errors decrease from $50 \%$, at $\mathrm{AOT}=0.05$, to $12 \%$ and $7 \%$ for $\mathrm{AOT}$ equal to 0.2 and 0.5 , respectively.

\section{Applying the Algorithm to Polder Instrument}

The above analysis shows the considerable potential to apply the algorithm and its advisability to be used with the data of the POLDER instrument. In a subsequent publication, we intend to present an Arctic-wide validation of our approach. This section shall illustrate the feasibility of the new algorithm to derive AOT and surface BRDF coefficients from POLDER measurements by comparing satellite-based 
retrievals with AERONET data. In [19] and [72], an example of an Arctic haze month in May 2006 has been shown. This Arctic haze month is reported to be caused by agricultural biomass burning in Europe and pollution in Russia [19]. The reoccurring haze events were according to the articles mentioned above are clearly observable above Spitsbergen. We, therefore, have applied the approach to POLDER observations for the whole of May 2006 collocated with the AERONET site Hornsund $(77.001 \mathrm{~N}, 15.540 \mathrm{E})$, which is located in the southern part of Spitsbergen. The POLDER cloud mask product was used and cloud-covered collocations have been excluded. Fig. 13 shows the comparison between the first POLDER-derived AOT and AERONET observations. There are several AOT peaks during May 2006. The first peak occurred on May 2-4, which has been reported in [74]. However, due to residual cloud cover, POLDER does not catch this peak. The second peak occurred on May 16-17 and POLDER-retrieved AOTs and AERONET observations show very promising agreement. There are several other small peaks and our retrieval shows good performance. Clear overestimations can be seen for several days (May 13) and this may be due to inaccurate cloud screening, aerosol typing, and surface parameterization. Fig. 14 shows a similar time series as Fig. 13 but for the whole year of 2006. According to Fig. 14, the Arctic haze phenomenon has been well-captured by the POLDER-derived AOT.

\section{CONCLUSION}

Due to large solar zenith angle, bright underlying surface, and on average low aerosol loading over the Arctic snow/icecovered regions, an AOT data coverage gap from passive remote sensing exists. Large uncertainty to understand the AA has been introduced due to a lack of AOT data over the cryosphere. In order to address this issue, a new AOT retrieval algorithm, in the framework of the XBAER algorithm, taking heritages of all existing knowledge, is proposed. This article intends to provide a comprehensive physical understanding of the key issues, aerosol typing, and surface reflection model, for the retrieval of AOT over the Arctic snow/ice-covered regions. Due to the coupling effect between the surface and aerosol information obtained by passive remote sensing instrument, e.g., POLDER, issues for both surface and aerosol parameterization need to be addressed by introducing proper retrieval constraints or a priori knowledge derived from other observations.

The aerosol properties over the Arctic regions are then analyzed using AERONET observations over representative sites. Optical properties (AOT and FMF) and microphysical properties (PSD and RI) over four Arctic sites were collected and analyzed. The AOT climatology at $550 \mathrm{~nm}$ for the selected sites leads to values between 0.05 and 0.11 with variabilities in the range of [0.02-0.12]. The FMF climatology leads to values generally larger than 0.9 , implying a significant contribution of fine-mode particles in the Arctic. The characteristics of Arctic aerosol particle size have been further investigated using the PSD retrieved from AERONET data. The PSD over the Arctic regions can be described by a bimodal lognormal distribution (one fine mode and one coarse mode). The PSD for Arctic haze conditions shows both smaller particles for both fine and coarse modes compared to the Arctic background (clean) case. The absorbing properties for both Arctic haze and clean cases have been analyzed using the imaginary part of RI, and the Arctic haze is accompanied by much higher values (about two times) compared to Arctic background condition.

As the prerequisite to extend the XBAER algorithm to Arctic regions, this article investigated the most recent development of the parameterization method for snow surface reflectance as described in [68], in which a new snow kernel (four-parametric method) is proposed based on the RossLi three-parametric model. The new method shows better performance, especially for the glint region compared to the Ross-Li method for atmosphere-free conditions. However, a very strong correlation between the four-parametric model and aerosol indicates significant problems in disentangling the contribution of aerosol from the surface. The usage of the Ross-Li three-parametric model shows to be an optimal surface parameterization which will be used later on in the XBAER algorithm [39].

Another key issue addressed in this article was an analysis to identify an adequate Arctic aerosol typing parameterization method, which represents, on average, the characteristics of Arctic aerosol size distribution and absorption suitable for AOT retrievals over the Arctic snow-covered regions. The PSD and RI climatology over Greenland has been derived using AERONET observation and used to represent the Arctic background and haze conditions in the forward simulations using SCIATRAN under the different surface and atmospheric conditions. The current XBAER aerosol typing parameterization as described in [39] is used in the retrieval. The investigation shows that both Arctic background and haze conditions can be well-captured by the WA aerosol type with an uncertainty of less than $15 \%$. The first attempt to use the algorithm on POLDER observations shows good performance compared to AERONET observations.

All the above investigations show that the combination of Ross-Li surface parameterization and WA aerosol typing can provide an optimal AOT retrieval algorithm over the Arctic snow/ice-covered regions.

\section{ACKNOWLEDGMENT}

The authors would like to thank R. S. Stone from the University of Colorado Boulder, Boulder, CO, USA, N. T. O'Neill from the Centre d'Applications et de Recherches en Télédétection, Université de Sherbrooke, Sherbrooke, QC, Canada, Dr. S. Sakerin from the V. E. Zuev Institute of Atmospheric Optics (Russian Federation), Tomsk, Russia, for valuable discussion, and Y. Che from the Chinese Academy of Sciences, Beijing, China. They would also like to thank the PIs of the Aerosol Robotic Network (AERONET) site used in this study for maintaining their instruments and providing their data and derivative products to the community.

\section{REFERENCES}

[1] M. C. Serreze and J. A. Francis, "The arctic amplification debate," Climatic Change, vol. 76, nos. 3-4, pp. 241-264, 2006. 
[2] J. A. Screen and I. Simmonds, "The central role of diminishing sea ice in recent Arctic temperature amplification," Nature, vol. 464, p. 1334, Apr. 2010

[3] M. Wendisch et al., "The arctic cloud puzzle: Using ACLOUD/PASCAL multiplatform observations to unravel the role of clouds and aerosol particles in arctic amplification," Bull. Amer. Meteorolog. Soc., vol. 100, pp. 841-871, May 2019.

[4] A. K. Liljedahl et al., "Pan-Arctic ice-wedge degradation in warming permafrost and its influence on tundra hydrology," Nature Geosci., vol. 9, no. 4, pp. 312-318, 2016

[5] T. Vihma et al., "The atmospheric role in the Arctic water cycle: A review on processes, past and future changes, and their impacts," J. Geophys. Res., Biogeosci, vol. 121, no. 3, pp. 586-620, 2016.

[6] A. Instanes, V. Kokorev, R. Janowicz, O. Bruland, K. Sand, and T. Prowse, "Changes to freshwater systems affecting Arctic infrastructure and natural resources," J. Geophys. Res. Biogeosci., vol. 121, no. 3 , pp. 567-585, Mar. 2016.

[7] J. Schmale et al., "Local Arctic air pollution: A neglected but serious problem," Earth's Future, vol. 6, no. 10, pp. 1385-1412, Oct. 2018.

[8] J. E. Overland et al., Surface Air Temperature in Arctic Report Card. Silver Spring, MD, USA: NOAA, 2018.

[9] D. K. Perovich et al., Sea Ice [in Arctic Report Card 2013]. Silver Spring, MD, USA: NOAA, 2018.

[10] S. J. Vavrus, "The influence of arctic amplification on mid-latitude weather and climate," Current Climate Change Rep., vol. 4, no. 3, pp. 238-249, Sep. 2018.

[11] C. Wobus, M. Flanner, M. C. Sarofim, M. C. P. Moura, and S. J. Smith, "Future arctic temperature change resulting from a range of aerosol emissions scenarios," Earth's Future, vol. 4, no. 6, pp. 270-281, Jun. 2016

[12] J. Hansen and L. Nazarenko, "Soot climate forcing via snow and ice albedos," Proc. Nat. Acad. Sci. USA, vol. 101, no. 2, pp. 423-428, Jan. 2004.

[13] V. Ramanathan and G. Carmichael, "Global and regional climate changes due to black carbon," Nature Geosci., vol. 1, no. 4, pp. 221-227, Apr. 2008.

[14] T. C. Bond et al., "Bounding the role of black carbon in the climate system: A scientific assessment," J. Geophys. Res. Atmos., vol. 118, no. 11, pp. 5380-5552, Jun. 2013.

[15] P. K. Quinn, G. Shaw, E. Andrews, E. G. Dutton, T. Ruoho-Airola, and S. L. Gong, "Arctic haze: Current trends and knowledge gaps," Tellus B, Chem. Phys. Meteorol., vol. 59, no. 1, pp. 99-114, Jan. 2007.

[16] T. J. Garrett and L. L. Verzella, "Looking back: An evolving history of arctic aerosols," Bull. Amer. Meteor. Soc., vol. 89, no. 3, pp. 299-302, Mar. 2008

[17] J. Schacht et al., "The importance of the representation of air pollution emissions for the modeled distribution and radiative effects of black carbon in the Arctic," Atmos. Chem. Phys., vol. 19, no. 17, pp. 11159-11183, Sep. 2019.

[18] K. A. Rahn, R. D. Borys, and G. E. Shaw, Asian Desert Dust Over Alaska: Anatomy of an Arctic Haze Episode Desert Dust: Origin, Characteristics, and Effect on Man, T. L. Péwé, Ed. Boulder, CO, USA Geological Society of America, 1981.

[19] R. S. Stone, G. P. Anderson, E. Andrews, E. G. Dutton, E. P. Shettle, and A. Berk, "Incursions and radiative impact of Asian dust in northern Alaska," Geophys. Res. Lett., vol. 34, no. 14, 2007, Art. no. L14815.

[20] L. Marelle et al., "Transport of anthropogenic and biomass burning aerosols from Europe to the Arctic during spring 2008," Atmos. Chem. Phys., vol. 15, no. 7, pp. 3831-3850, Apr. 2015.

[21] Y. Wang et al., "Elucidating the role of anthropogenic aerosols in Arctic sea ice variations," J. Climate, vol. 31, no. 1, pp. 99-114, Jan. 2018.

[22] M. Dall'Osto et al., "Simultaneous measurements of aerosol size distributions at three sites in the European high Arctic," Atmos. Chem. Phys., vol. 19, pp. 7377-7395, 2019, doi: 10.5194/acp-19-7377-2019.

[23] C. Tomasi et al., "Aerosol remote sensing in polar regions," Earth Sci. Rev., vol. 140, pp. 108-157, Jan. 2015, doi: 10.1016/j.earscirev. 2014.11.001.

[24] A. Gabric, P. Matrai, G. Jones, and J. Middleton, "The nexus between sea ice and polar emissions of marine biogenic aerosols," Bull. Amer. Meteor. Soc., vol. 99, no. 1, pp. 61-81, Jan. 2018.

[25] K.-T. Park et al., "Atmospheric DMS in the arctic ocean and its relation to phytoplankton biomass," Global Biogeochem. Cycles, vol. 32, no. 3, pp. 351-359, Mar. 2018.

[26] K. S. Law et al., "Local arctic air pollution: Sources and impacts," Ambio, vol. 46, no. 3, pp. 453-463, Dec. 2017.
[27] D. Lack, Transport Emissions: Air Quality and Climate Consulting. QLD, Australia, 2016. [Online]. Available: https://www.hfofreearctic.org/wp-content/uploads/2016/10/The-Impactsof-an-Arctic-Shipping-HFO-Ban-on-Emissions-of-Black-Carbon.pdf

[28] D. A. Lack and J. J. Corbett, "Black carbon from ships: A review of the effects of ship speed, fuel quality and exhaust gas scrubbing," Atmos. Chem. Phys., vol. 12, no. 9, pp. 3985-4000, May 2012.

[29] S. Eckhardt et al., "The influence of cruise ship emissions on air pollution in Svalbard-A harbinger of a more polluted Arctic?" Atmos. Chem. Phys., vol. 13, no. 16, pp. 8401-8409, Aug. 2013.

[30] G. S. W. Hagler, M. H. Bergin, E. A. Smith, M. Town, and J. E. Dibb, "Local anthropogenic impact on particulate elemental carbon concentrations at summit, Greenland," Atmos. Chem. Phys., vol. 8, no. 9, pp. 2485-2491, Apr. 2010

[31] M. Wendisch et al., "Understanding causes and effects of rapid warming in the Arctic," Eos, vol. 98, pp. 22-26, Jan. 2017, doi: 10.1029/2017EO064803.

[32] E. Freud et al., "Pan-Arctic aerosol number size distributions: Seasonality and transport patterns," Atmos. Chem. Phys., vol. 17, no. 13, pp. 8101-8128, Jul. 2017.

[33] K. Zhang et al., "The global aerosol-climate model ECHAM-HAM, version 2: Sensitivity to improvements in process representations," Atmos. Chem. Phys., vol. 12, no. 19, pp. 8911-8949, Oct. 2012, doi: 10.5194/ acp-12-8911-2012.

[34] I. Tegen et al., "The global aerosol-climate model ECHAM6.3HAM2.3-Part 1: Aerosol evaluation," Geosci. Model Dev., vol. 12, pp. 1643-1677, 2019, doi: 10.5194/gmd-12-1643-2019.

[35] J. Von Hardenberg et al., "Aerosol optical depth over the Arctic: A comparison of ECHAM-HAM and TM5 with ground-based, satellite and reanalysis data," Atmos. Chem. Phys., vol. 12, no. 15, pp. 6953-6967, Aug. 2012, doi: 10.5194/acp-12-6953-2012.

[36] L. G. Istomina, W. von Hoyningen-Huene, A. A. Kokhanovsky, E. Schultz, and J. P. Burrows, "Remote sensing of aerosols over snow using infrared AATSR observations," Atmos. Meas. Tech., vol. 4, no. 6, pp. 1133-1145, Jun. 2011

[37] L. Mei et al., "Aerosol optical depth retrieval in the Arctic region using MODIS data over snow," Remote Sens. Environ., vol. 128, pp. 234-245, Jan. 2013

[38] L. Mei et al., "Aerosol optical depth retrieval over snow using AATSR data," Int. J. Remote Sens., vol. 34, no. 14, pp. 5030-5041, Jul. 2013.

[39] L. Mei, V. Rozanov, M. Vountas, J. P. Burrows, R. C. Levy, and W. Lotz, "Retrieval of aerosol optical properties using MERIS observations: Algorithm and some first results," Remote Sens. Environ., vol. 197, pp. 125-140, Aug. 2017.

[40] L. Mei et al., "A Cloud masking algorithm for the XBAER aerosol retrieval using MERIS data," Remote Sens. Environment, vol. 197, pp. 141-160, Aug. 2017

[41] L. Mei, V. Rozanov, M. Vountas, J. P. Burrows, and A. Richter, "XBAER-derived aerosol optical thickness from OLCI/Sentinel-3 observation," Atmos. Chem. Phys., vol. 18, no. 4, pp. 2511-2523, Feb. 2018

[42] L. Mei, V. Rozanov, M. Vountas, and J. P. Burrows, "The retrieval of ice cloud parameters from multi-spectral satellite observations of reflectance using a modified XBAER algorithm," Remote Sens. Environ., vol. 215, pp. 128-144, Sep. 2018.

[43] L. Mei et al., "Extending XBAER algorithm to aerosol and cloud condition," IEEE Trans. Geosci. Remote Sens., vol. 57, no. 10, pp. 8262-8275, Oct. 2019, doi: 10.1109/TGRS.2019.2919910.

[44] B. Holben et al., "AERONET-A federated instrument network and data archive for aerosol characterization," Remote Sens. Environ., vol. 66, no. 1 , pp. 1-16, Oct. 1998

[45] Y. J. Kaufman, D. Tanré, and O. Boucher, "A satellite view of aerosols in the climate system," Nature, vol. 419, no. 6903, pp. 215-223, Sep. 2002.

[46] G. G. Persad and K. Caldeira, "Divergent global-scale temperature effects from identical aerosols emitted in different regions," Nature Commun., vol. 9, no. 1, p. 3289, Aug. 17, 2018

[47] A. J. Cohen et al., "Estimates and 25-year trends of the global burden of disease attributable to ambient air pollution: An analysis of data from the global burden of diseases study 2015," Lancet, vol. 389, no. 10082 pp. 1907-1918, May 2017.

[48] N. T. O'Neill, O. Dubovik, and T. F. Eck, "Modified Ångström exponent for the characterization of submicrometer aerosols," Appl. Opt., vol. 40, no. 15, p. 2368, May 2001

[49] N. T. O'neill, T. F. Eck, B. N. Holben, A. Smirnov, O. Dubovik, and A. Royer, "Bimodal size distribution influences on the variation of Angstrom derivatives in spectral and optical depth space," J. Geophys. Res., vol. 106, no. D9, pp. 9787-9806, May 2001. 
[50] N. T. O’Neill, T. F. Eck, A. Smirnov, B. N. Holben, and S. Thulasiraman, "Spectral discrimination of coarse and fine mode optical depth," J. Geophys. Res. Atmos., vol. 108, no. D17, 4559, doi: 10.1029/2002JD002975.

[51] N. Bellouin, O. Boucher, J. Haywood, and M. S. Reddy, "Global estimate of aerosol direct radiative forcing from satellite measurements," Nature, vol. 438, no. 7071, pp. 1138-1141, Dec. 2005, doi: 10.1038/ nature 04348

[52] X. Yan, Z. Li, W. Shi, N. Luo, T. Wu, and W. Zhao, "An improved algorithm for retrieving the fine-mode fraction of aerosol optical thickness, part 1: Algorithm development," Remote Sens. Environ., vol. 192, pp. 87-97, Apr. 2017

[53] D. M. Giles et al., "Advancements in the aerosol robotic network (AERONET) Version 3 database-Automated near-real-time quality control algorithm with improved cloud screening for Sun photometer aerosol optical depth (AOD) measurements," Atmos. Meas. Techn. vol. 12, no. 1, pp. 169-209, 2019.

[54] A. Smirnov, T. Zhuravleva, M. Segal-Rosenheimer, and B. Holben, "Limitations of AERONET SDA product in presence of cirrus clouds," J. Quant. Spectrosc. Radiat. Transf., vol. 206, pp. 338-341, Feb. 2018.

[55] Y. Liu and F. Liu, "On the description of aerosol particle size distribution," Atmos. Res., vol. 31, nos. 1-3, pp. 187-198, Jan. 1994.

[56] F. Kottler, "The distribution of particle sizes," J. Franklin Inst., vol. 250, no. 5, pp. 419-441, Nov. 1950

[57] H. L. Green and W. R. Lane, Panicle Clouds: Dusts, Smokes and Mists, 2nd ed. Belfast, Northern Ireland: Univ. Press, 1964

[58] C. Junge, Air Chemistry and Radioactivity. New York, NY, USA Academic, 1963.

[59] L. A. Remer and Y. J. Kaufman, "Dynamic aerosol model: Urban/industrial aerosol," J. Geophys. Res., vol. 103, no. D12, pp. 13859-13871, Jun. 1998.

[60] O. Dubovik et al., "Variability of absorption and optical properties of key aerosol types observed in worldwide locations," J. Atmos. Sci., vol. 59, no. 3, pp. 590-608, Feb. 2002.

[61] O. Dubovik et al., "Accuracy assessments of aerosol optical properties retrieved from aerosol robotic network (AERONET) sun and sky radiance measurements," J. Geophys. Res., vol. 105, no. D8, pp. 9791-9806, Apr. 2000, doi: 10.1029/2000jd900040.

[62] K. J. Zarzana, C. D. Cappa, and M. A. Tolbert, "Sensitivity of aerosol refractive index retrievals using optical spectroscopy," Aerosol Sci. Technol., vol. 48, no. 11, pp. 1133-1144, Nov. 2014.

[63] R. S. Stone, S. Sharma, A. Herber, K. Eleftheriadis, and D. W. Nelson, "A characterization of Arctic aerosols on the basis of aerosol optical depth and black carbon measurements," Elementa, Sci. Anthropocene, vol. 2, Jun. 2014, Art. no. 000027.

[64] X. Wang et al., "Deriving brown carbon from multiwavelength absorption measurements: Method and application to AERONET and Aethalometer observations," Atmos. Chem. Phys., vol. 16, no. 19, pp. 12733-12752, Oct. 2016.

[65] K. Huang et al., "Russian anthropogenic black carbon: Emission reconstruction and Arctic black carbon simulation," J. Geophys. Res. Atmos., vol. 120, no. 21, pp. 11,306-11,333, Nov. 2015.

[66] E. Asmi et al., "Aerosol size distribution seasonal characteristics measured in Tiksi, Russian Arctic," Atmos. Chem. Phys., vol. 16, no. 3, pp. 1271-1287, Feb. 2016.

[67] W. Lucht, C. Schaaf, and A. Strahler, "An algorithm for the retrieval of albedo from space using semiempirical BRDF models," IEEE Trans. Geosci. Remote Sens., vol. 38, no. 2, pp. 977-998, Mar. 2000.

[68] Z. Jiao et al., "Development of a snow kernel to better model the anisotropic reflectance of pure snow in a kernel-driven BRDF model framework," Remote Sens. Environ., vol. 221, pp. 198-209, Feb. 2019.

[69] F.-M. Breon and F. Maignan, "A BRDF-BPDF database for the analysis of Earth target reflectances," Earth Syst. Sci. Data, vol. 9, pp. 31-45, Jan. 2017, doi: 10.5194/essd-9-31-2017.

[70] B.-M. Sinnhuber, N. Sheode, M. Sinnhuber, M. P. Chipperfield, and W. Feng, "The contribution of anthropogenic bromine emissions to past stratospheric ozone trends: A modelling study," Atmos. Chem. Phys., vol. 9, no. 8, pp. 2863-2871, Apr. 2010.

[71] V. Rozanov, A. Rozanov, A. Kokhanovsky, and J. Burrows, "Radiative transfer through terrestrial atmosphere and ocean: Software package SCIATRAN," J. Quant. Spectrosc. Radiat. Transf., vol. 133, pp. 13-71, Jan. 2014.

[72] M. Stock et al., "Springtime Arctic aerosol: Smoke versus haze, a case study for March 2008," Atmos. Environ., vol. 52, pp. 48-55, Jun. 2012. [Online]. Available: http://www.sciencedirect.com/science/ article/pii/S1352231011006637, doi: 10.1016/j.atmosenv.2011.06.051.
[73] Z. Shi, T. Xing, J. Guang, Y. Xue, and Y. Che, "Aerosol optical depth over the arctic snow-covered regions derived from dual-viewing satellite observations," Remote Sens., vol. 11, no. 8, p. 891, Apr. 2019.

[74] C. D. Rodgers, Inverse Methods for Atmospheric Sounding: Theory and Practice, vol. 2. Singapore: World Scientific, 2000.

[75] V. V. Rozanov, A. V. Rozanov, and A. A. Kokhanovsky, "Derivatives of the radiation field and their application to the solution of inverse problems," in Light Scattering Reviews, vol. 2. Berlin, Germany: Springer-Verlag, 2007.

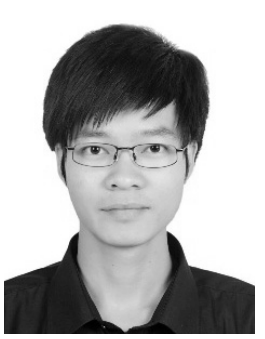

Linlu Mei received the B.S. degree in geographic information system from the China University of Geosciences, Wuhan, China, in 2008, and the Ph.D. degree in atmospheric remote sensing from the Institute of Remote Sensing and Digital Earth, Chinese Academy of Sciences (CAS), Beijing, China, under the Joint Doctoral Training Program between the University of Bremen, Bremen, Germany, and CAS, in 2013

$\mathrm{He}$ is currently a Senior Researcher with the Institute of Environmental Physics and Remote Sensing, University of Bremen. He is the Leading Developer of the eXtensible Bremen Aerosol/cloud and surfacE Retrieval (XBAER) algorithm, which can be used to derive atmospheric (aerosol and cloud) and surface properties globally. He has authored more than 40 peer-reviewed articles. He has 663 citations and H-index 15 (source: Google Scholar). His research interests include radiative transfer theory, aerosol/cloud/surface retrieval, long-term satellite product creation, regional air quality monitoring, and long-term trend analysis.

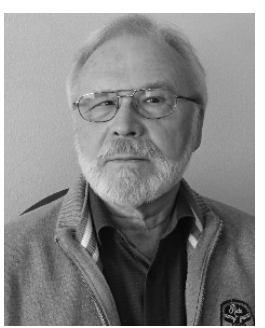

Vladimir Rozanov received the M.S. and Ph.D degrees in physics and mathematics from the University of St. Petersburg, St. Petersburg, Russia, in 1974 and 1978, respectively.

He is currently the Scientific Consultant to Prof. Burrows on radiative transfer and retrieval theory. He has been active in research since 1974. He was the Main Developer of the radiative transfer model GOMETRAN and the Leading Developer of its successor SCIATRAN. He has authored 116 peerreviewed articles on the radiative transfer modeling, retrieval of atmospheric species from remote sensing measurements, and atmospheric composition. He has 3048 citations and H-index 24 (source: Web of Knowledge). His main research interests are the interpretation of the remote sensing measurements of the Earth's atmosphere and the radiative transfer modeling. He is currently focusing on the implementation of the new features in the SCIATRAN radiative transfer model and provides a scientific support to ensure the optimal usage of SCIATRAN by the team members of the Institute of Environmental Physics (IUP), University of Bremen, Bremen, Germany.

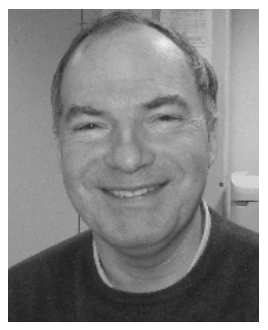

Christoph Ritter received the Ph.D. degree in solar physics observations of polar faculae from Göttingen University, Göttingen, Germany, in 2001.

$\mathrm{He}$ has been a Research Scientist with the Atmospheric Circulation Section, Alfred Wegener Institut, Potsdam, Germany, since 2001. He has been participating in many international campaigns in Ny-Ålesund since 2002 and has been supervising $4 \mathrm{Ph} . \mathrm{D}$. and several diploma and master's thesis since 2006. He is also a Representative of Alfred Wegener Institute for Polar and Marine Research (AWI) in national and international boards and the Lead of different international campaigns on aerosol in Spitsbergen. His research interests include LiDAR technology and LiDAR data evaluation, remote sensing, aerosol research, arctic meteorology, and boundary layer research. 


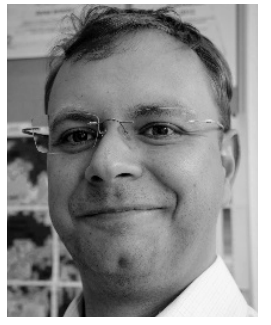

Bernd Heinold received the Diploma degree (equivalent to a master's degree) and the Ph.D. degree in meteorology from the University of Leipzig, Leipzig, Germany, in 2004 and 2008, respectively.

During his Ph.D., he worked as a Research Assistant and then began work as a Research Fellow with the Leibniz Institute for Tropospheric Research (TROPOS), Leipzig. In 2011, he joined the School of Earth and Environment, University of Leeds, Leeds, U.K., as a Research Fellow, for two years. Since 2013, he has been a Scientist with the Leibniz Institute for Tropospheric Research (TROPOS). He develops and evaluates representations of aerosol processes in atmospheric models from large-eddy to global scale. He has authored or coauthored more than 120 publications, including over 50 articles in different international, peer-reviewed science journals. His research interests include tropospheric aerosol particles and their impact on climate and air quality, with particular focus on mineral dust and black carbon aerosol.

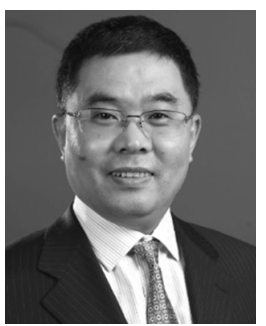

Ziti Jiao received the B.Sc. degree in mining engineering from the Wuhan Institute of Technology, Wuhan, China, in 1993, the M.Sc. degree from the School of Geography, Beijing Normal University (BNU), Beijing, China, in 2002, the Ph.D. degree in geographic information system from BNU, in 2008 , and the Ph.D. degree in remote sensing from Boston University (BU), Boston, MA, USA, in 2009 through the exchange program between BNU and BU in 2004.

He is currently a Professor with the Institute of Remote Sensing Science and Engineering, Faculty of Geographical Science, BNU. His research interests mainly include modeling reflectance anisotropy and albedo using remotely sensed data to monitor the reflectance characteristics of various land surfaces. More recently, he has been focusing on the development of the kernel-driven bidirectional reflectance distribution function (BRDF) models, including modeling hotspot effect and snow scattering optics in the kernel-driven BRDF model framework. He is currently working on the development of the operational clumping index $(\mathrm{CI})$ products to monitor the Earth's environments using the multiangle signatures.

Dr. Jiao serves as a Reviewer for Remote Sensing of Environment and the IEEE Transactions on Geoscience and Remote Sensing. He is currently the Editorial Board Member of Remote Sensing.

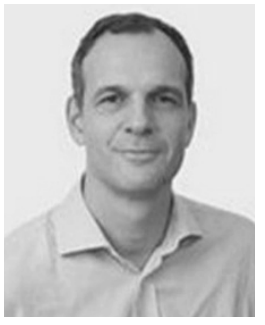

Marco Vountas received the Diploma degree in electronics/telecommunications from the University of Bremen, Bremen, Germany, in 1994, and the $\mathrm{Ph} . \mathrm{D}$. degree in physics from the Institute of Environmental Physics (IUP), University of Bremen, in 1998.

From 1998 to 1999, he was a Post-Doctoral Researcher with IUP. Until 2000, he worked as an Internet Provider with mediaWays (now Telefonica.de), Bremen. Until 2001, he was with OHBTelemondo, Bremen, a space company. Since 2001, he has been a Scientist with IUP, dealing with retrievals of aerosol and aquatic optical parameters from spaceborne data as well as inelastic scattering within radiative transfer modeling. He coordinates scientific computing as well as IT-relevant issues.

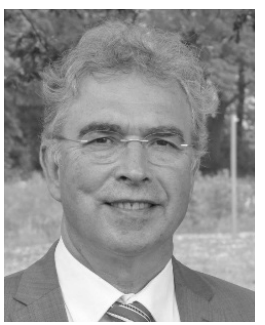

John P. Burrows received the B.A. degree (Hons.) in natural sciences from the West Park Grammar School Merseyside, Saint Helens, U.K., in 1975, and the M.A. and Ph.D. degrees from Trinity College, Cambridge University, Cambridge, U.K., in 1978 and 1979, respectively.

He was a Post-Doctoral Researcher with the Harvard-Smithsonian Center for Astrophysics, Cambridge, MA, USA. He became a Staff Member with U.K. AERE Harwell, Oxfordshire, U.K., and a Research Scientist with the Physical Chemistry Laboratory, University of Oxford, Oxford, U.K. In 1982, he joined the Max Planck Institute for Chemistry (Director Prof. Dr. P. J. Crutzen), Mainz, Germany. Since 1992, he has been a Professor of physics of the ocean and atmosphere with the University of Bremen, Bremen, Germany, where he cofounded and now directs the Institute of Environmental Physics/Institute of Remote Sensing. He has been a Regular Guest Scientist at NASA and was seconded from 2008 to 2010 to be the Science Director Biogeochemistry at NERC:CEH, Oxfordshire, and becoming a fellow in 2010. He has contributed to our scientific understanding of air pollution, the ozone layer, the upper atmosphere, biogeochemistry, and climate change. He and his coworkers have studied the kinetics and spectroscopy of key atmospheric free radicals and gases, developed innovative in situ trace atmospheric measurement techniques, and pioneered the passive remote sensing of atmospheric constituents and surface parameters. Working closely with DLR, ESA, and NASA, he initiated and led scientifically the SCIAMACHY Project, which resulted in the satellite-based measurements of the instruments GOME on ESA ERS2 from 1995 to 2011, SCIAMACHY on ESA ENVISAT from 2002 to 2012 GOME-2 on EUMETSAT Metop Series from 2006 to 2022, and the concepts GeoSCIA/GeoTROPE, now developed as EU Copernicus Sentinel 4 and CarbonSat/CarbonSat Constellation.

Dr. Burrows is a fellow of AAAS, AGU, IUGG, and NERC:CEH, and a member of IAA. He was a recipient of the COSPAR William Nordberg Medal in 2006, the NASA Group Achievement Award in 2008, the JQSRT Milestone Paper Award in 2010, the Haagen-Smit Prize in 2012, the EGU Vilhelm Bjerknes Medal in 2013, the IUGG Silver Medal IUGG in 2015, and the Alfred Wegener Medal EGU in 2016. 